\title{
Expression of Transcripts Encoding AMPA Receptor Subunits and Associated Postsynaptic Proteins in the Macaque Brain
}

\author{
MONICA BENEYTO* AND JAMES H. MEADOR-WOODRUFF \\ Mental Health Research Institute and Department of Psychiatry, University of Michigan, \\ Ann Arbor, Michigan, 48109
}

\begin{abstract}
Glutamate is the primary excitatory neurotransmitter in the central nervous system, regulating numerous cellular signaling pathways and controlling the excitability of central synapses both pre- and postsynaptically. Localization, cell surface expression, and activitydependent regulation of glutamate receptors in both neurons and glia are performed and maintained by a complex network of protein-protein interactions associated with targeting, anchoring, and spatially organizing synaptic proteins at the cell membrane. Using in situ hybridization, we examined the expression of transcripts encoding the AMPA receptor subunits (GluR1-GluR4) and a family of AMPA-related intracellular proteins. We focused on PDZ-proteins that are involved in the regulated pool and anchoring AMPA subunits to the cell membrane (PICK1, syntenin), and those maintaining the constitutive pool of AMPA receptors at the glutamatergic synapse (NSF, stargazin). In addition, we studied a fifth protein, KIAA1719, with high homology to the rat PDZ protein ABP, associated with the clustering of AMPA receptors at the glutamate synapse. The AMPA subunits showed significant differences in regional expression, especially in the neocortex, thalamus, striatum, and cerebellum. The expression of other proteins, even those related to a specific AMPA subunit (such as ABP and PICK1 to GluR2 and GluR3), often had different distributions, whereas others (like NSF) are ubiquitously distributed in the brain. These results suggest that AMPA subunits and related intracellular proteins are differentially distributed in the macaque brain, and in numerous structures there are significant mismatches, suggesting additional functional properties of the associated intracellular proteins. J. Comp. Neurol. 468:530-554, 2004. ๑ 2003 Wiley-Liss, Inc.
\end{abstract}

Indexing terms: glutamate; ionotropic receptors; postsynaptic density proteins; regulated pool; constitutive pool; in situ hybridization

Ionotropic glutamate receptors mediate most of the fast excitatory neurotransmission in the mammalian brain. Based on molecular, pharmacological, and physiological observations the ionotropic glutamate receptors have been classified into three different subtypes: AMPA ( $\alpha$-amino-3hydroxy-5-methyl-4-isoxazole propionate), kainate, and NMDA (N-methyl-D-aspartate) receptors. Glutamate binding to AMPA receptors mediates the majority of lowfrequency transmission at glutamatergic synapses. Changes in AMPA receptor-mediated transmission underlie several developmental and adult types of synaptic plasticity, including long-term potentiation (LTP) and depression (LTD) (Bliss and Collingridge, 1993; Isaac et al., 1995; Linden and Connor, 1995; Selig et al., 1995; Bear and Abraham, 1996).
AMPA receptors are heteromeric assembles composed of up to four different subunits, GluR1-GluR4 (Wenthold et al., 1992; Brose et al., 1994; Puchalski et al., 1994). The

Grant sponsor: NIMH; Grant number: MH53327 (J.H.M.-W.).

*Correspondence to: Monica Beneyto, Mental Health Research Institute and Department of Psychiatry. University of Michigan, 205 Zina Pitcher Place, Ann Arbor, MI, 48109. E-mail: mbeneyto@umich.edu.

Received 20 June 2003; Revised 2 September 2003; Accepted 5 September 2003

DOI 10.1002/cne.10981

Published online the week of December 1, 2003 in Wiley InterScience (www.interscience.wiley.com). 
stoichiometry of these subunits determines many physiological properties of the receptor, including calcium permeability, desensitization kinetics, channel opening time, and receptor internalization and turnover from the postsynaptic membrane (Shi et al., 2001). Recent studies have shown significant differences in the regulation of synaptic expression of the two main ionotropic glutamate receptors, NMDA and AMPA. Although NMDA and AMPA receptors largely colocalize in excitatory synapses (Huntley et al., 1994; Kharazia et al., 1996; Takumi et al., 1999b; Gonzalez-Albo and DeFelipe, 2000), NMDA receptors are relatively stable in the postsynaptic cell membrane with minimum recycling, while AMPA receptors are dynamically regulated into and off of the membrane in an activity-dependent manner. AMPA receptor insertion into and removal from the postsynaptic membrane and stabilization in the postsynaptic density (PSD) are controlled by specific subunit protein interactions and play an important role in synaptic plasticity.

Although there is considerable homology among the four transmembrane and extracellular domains of the AMPA receptor subunits, all of them have specific cytoplasmic carboxyl termini that are either long (GluR1 and GluR4) or short (GluR2 and GluR3) (Kohler et al., 1994b). These C-termini determine which intracellular proteins that mediate AMPA receptor trafficking and signal transduction interact with specific receptor subunits in the PSD (Sheng and Pak, 2000; Shi et al., 2001). These proteins interact via PDZ domains, named for three proteins that possess this motif: PSD-95 (Cho et al., 1992), its homolog Drosophila disc-large tumor suppressor gene (Dlg-A) product (Lue et al., 1994), and ZO-1, a tight junction protein (Itoh et al., 1993). The PDZ domains in these proteins are motifs of about 90 amino acids (D'Eustachio, 1994) and have been suggested to play a role in receptor targeting and localization in the synapse by specifically binding the C-termini of a variety of membrane proteins, including neurotransmitter receptors (Ehlers et al., 1996; Sheng, 1996; Sheng and Kim, 1996; Kornau et al., 1997). PDZ domains are also localized within the C-terminal regions of all four AMPA receptor subunits (Braithwaite et al., 2000; Sheng and Lee, 2001), allowing them to interact with a variety of PSD proteins.

The GluR2 subunit has an extreme C-terminal-PDZ binding motif that interacts with at least three PDZ domain-containing proteins: GRIP1 (glutamate receptorinteracting protein 1) (Dong et al., 1997), ABP (AMPA receptor-binding protein) (with one isoform known as GRIP2) (Srivastava et al., 1998; Braithwaite et al., 2002), and PICK1 (protein interacting with $\mathrm{C}$ kinase 1) (Dev et al., 1999; Xia et al., 1999). GRIP1 and ABP have been shown to interact with both GluR2 and GluR3 in vitro (Dong et al., 1999) and in vivo (Burette et al., 1999). PICK1 also binds to the C-termini of the GluR2 and GluR3 subunits. It has a single PDZ domain that can bind PKC $\alpha$ (Staudinger et al., 1997) and GluR2/3, and another site that is a putative substrate for PKC phosphorylation. PICK1 can form dimers via two proximal PDZ domains, and thus may facilitate the clustering of AMPA receptors at the postsynaptic membrane and/or the regulation of PKC-dependent phosphorylation of the AMPA receptor subunits (McGlade-McCulloh et al., 1993; Dev et al., 1999; Xia et al., 1999; Chung et al., 2000; Daw et al., 2000; Henley, 2001).

Recently, several in vitro analyses have identified a new PDZ protein, syntenin. This protein was first identified based on its interaction with syndecans (Grootjans et al., 1997). It has two PDZ domains that bind some of the proteins recognized by GRIP and PICK1 (EphrinB1, EphA7), but also has specific interactions (EphB2). Similar to PICK1, syntenin can dimerize, but the substrate of dimerization is still unknown. Syntenin can interact with all four AMPA receptor subunits and with mGluR7 (Hirbec et al., 2002).
Abbreviations

$\begin{array}{ll}\text { ABA } & \text { accessory basal nucleus of the amygdala } \\ \text { ABP AMPA } & \begin{array}{l}\text { receptor binding protein } \\ \text { nucleus accumbens }\end{array} \\ \text { Acc } & \text { basal nucleus of the amygdala } \\ \text { BA } & \text { caudate nucleus } \\ \text { CA } & \text { field of Ammon's horn } \\ \text { CA1 CA1 } & \text { field of Ammon's horn } \\ \text { CA2 CA2 } & \text { field of Ammon's horn } \\ \text { CA3 CA3 } & \text { field of Ammon's horn } \\ \text { CA4 CA4 } & \text { calmodulin kinase II } \\ \text { CaMKII } & \text { central amygdaloid nucleus } \\ \text { CeA } & \text { central gray substance of the pons } \\ \text { CGP } & \text { claustrum } \\ \text { Cl } & \text { anterior cortical nucleus of the amygdala } \\ \text { CoA } & \text { caudal pontine reticular nucleus } \\ \text { CPn } & \text { dorsal cochlear nucleus } \\ \text { DCN } & \text { dentate gyrus } \\ \text { DG } & \text { inferior colliculus } \\ \text { IC } & \text { glutamate receptor interacting protein } \\ \text { GRIP } & \text { globus pallidus } \\ \text { GP } & \text { external segment of the globus pallidus } \\ \text { GPe } & \text { internal segment of the globus pallidus } \\ \text { GPi } & \text { hippocampal formation } \\ \text { HiF } & \text { lateral amygdaloid nucleus } \\ \text { LA } & \text { lateral parabrachial nucleus } \\ \text { LPB } & \text { lateral superior olivary nucleus } \\ \text { LSO } & \text { long-term depression } \\ \text { LTD } & \text { long-term potentiation } \\ \text { LTP } & \end{array}$

medial amygdaloid nucleus

medial superior olivary nucleus

$\mathrm{N}$-ethylmaleimide sensitive fusion protein

protein interacting with C-kinase a

paramygdaloid area

paraventricular nucleus of the anterior hypothalamic region

protein kinase A

protein kinase $\mathrm{C}$

pontine nuclei

presubiculum

putamen

postsynaptic density

pontine raphe nucleus

subthalamic nucleus

superior colliculus

substantia innominata

substantia nigra

substantia nigra pars compacta

substantia nigra pars reticulata

stargazin

subiculum

syntenin

trapezoid nuclei

trapezoid body

ventral cochlear nuclei

ventromedial nucleus of hypothalamus 
The proteins involved in the postsynaptic trafficking, targeting, and anchoring of the AMPA receptors also include non-PDZ domain-containing proteins. Biochemical fractionation has shown that $\mathrm{N}$-ethylmaleimide-sensitive fusion protein (NSF) interacts with the C-terminus of GluR2 in vitro. It has been suggested that it regulates the recycling of AMPA receptors at the synapse and AMPA receptor function (Song et al., 1998). Another protein without PDZ domains, stargazin, binds to all four AMPA subunits and has been identified as a mediator in a two-step trafficking model, in which it first conveys AMPA receptors to the neuronal surface, and then sweeps them laterally into postsynaptic sites. This second step requires an interaction of the carboxyl terminus of stargazin with one of the PDZ anchoring proteins (Chen et al., 2000). Several studies have been conducted in vitro to characterize these molecules and their interactions, but few studies have demonstrated their expression in brain, particularly in regions such as the hippocampus, cerebellum, and cortex (Puschel et al., 1994; Chen et al., 2000). In this work, we mapped the transcripts encoding all four of the AMPA receptor subunits, GluR1-GluR4, in the macaque brain. In addition, we examined the distribution of transcripts encoding five intracellular proteins related to the AMPA receptors: NSF, PICK1, stargazin, syntenin, as well as KIAA1719, a previously undescribed molecule in the human with high homology to the rat gene ABP. This is the first comprehensive in vivo study that examines the regional expression in the primate brain of the transcripts encoding the four AMPA receptor subunits and a family of proteins that regulates their trafficking and anchoring in the postsynaptic membrane.

\section{MATERIALS AND METHODS Animals and tissue preparation}

This study was carried out on matched $10-\mu \mathrm{m}$ frozen sections obtained from brains of four female macaques (Macaca nemestrina) ranging in age from 7-13 years. These brains were obtained from the Regional Primate Research Center of the University of Washington. These animals were sacrificed as part of projects unrelated to the present study which did not require brain tissue. Protocols involving these animals were reviewed by the Washington Regional Primate Research Review Committee and by the University of Washington IACUC. Each brain was blocked in the coronal plane into five $1.5-\mathrm{cm}$ slabs comprising the full extent of the brain from the frontal lobe through the cerebellum and occipital cortex. Blocks were stored at $-80^{\circ} \mathrm{C}$ until cryostat sectioning. Sections were mounted onto poly-L-lysine-subbed glass microscope slides, desiccated, and stored at $-80^{\circ} \mathrm{C}$ until use.

\section{In situ hybridization histochemistry}

GluR1 and GluR2 transcripts were studied using previously described subclones (Ibrahim et al., 2000a, b; Meador-Woodruff et al., 2001). We prepared new subclones using PCR and a human brain cDNA library for the GluR3 and GluR4 subunits and the related intracellular proteins NSF, PICK1, stargazin, syntenin, and KIAA1719. The subclones ranged from $176-586$ bases and had similar G/C ratios $(<50 \%)$, encoding specific fragments of each sequence (Table 1). PCR-amplified cDNA segments were extracted (QIAquick Gel Extraction Kit,
TABLE 1. Probe Characteristics

\begin{tabular}{lccc}
\hline Gene & Accession number & $\begin{array}{c}\text { Number of bases } \\
\text { in probe }(\mathrm{bp})\end{array}$ & $\begin{array}{c}\text { Region of gene } \\
\text { in probe }\end{array}$ \\
\hline GluR1* & NM_031608 & 507 & $1-507$ \\
GluR2* & M85035 & 534 & $823-1,357$ \\
GluR3 & U10301 & 405 & $560-964$ \\
GluR4 & XM_006233 & 176 & $366-541$ \\
NSF & NM_006178 & 468 & $1745-2,212$ \\
PICK-1 & AL049654 & 586 & $1160-1,745$ \\
Stargazin & XM_009955 & 453 & $495-947$ \\
Syntenin & XM_044627 & 396 & $492-888$ \\
KIAA1719 & XM_042936 & 298 & $5-302$ \\
\hline
\end{tabular}

*Rattus norvergicus sequences.

Qiagen, Valencia, CA), subcloned (Zero Blunt TOPO PCR cloning kit, Invitrogen, Carlsbad, CA), and confirmed by nucleotide sequencing.

Sense and antisense riboprobes were synthesized using $100 \mu \mathrm{Ci}$ of dried [ $\left.{ }^{35} \mathrm{~S}\right]-\mathrm{UTP}, 2.0 \mu \mathrm{l} 5 \times$ transcription buffer (40 mM Tris-base, $6 \mathrm{mM} \mathrm{MgCl}_{2}, 2 \mathrm{mM}$ spermidine, $10 \mathrm{mM}$ $\mathrm{NaCl}, \mathrm{pH}$ 7.9) $1 \mu \mathrm{l} 0.1 \mathrm{M}$ DTT, $1 \mu \mathrm{l}$ each of $10 \mathrm{mM}$ ATP, CTP, and GTP, $1 \mu \mathrm{g}$ of linearized plasmid DNA, $0.5 \mu \mathrm{l}$ RNA inhibitor, and $1.5 \mu$ l of SP6, T3 or T7 RNA polymerase. After incubating for 2 hours at $37^{\circ} \mathrm{C}, 1.0 \mu \mathrm{l}$ DNAse (RNAse-free) was added and incubated for 15 minutes at room temperature. The reaction mixture was then sieved through chromatography columns (Micro Bio-Spin P-30 Tris Chromatography Columns, Bio-Rad Laboratories, Richmond, CA) and the purified fractions were eluted. DTT was added to each fraction to a final concentration of $0.01 \mathrm{M}$.

After fixing the mounted frozen sections by placing the slides in $4 \%$ (weight:volume) formaldehyde for 1 hour at room temperature, they were briefly rinsed in $2 \times \mathrm{SSC}$ (standard saline citrate, $300 \mathrm{mM}$ sodium chloride, and 30 $\mathrm{mM}$ sodium citrate, $\mathrm{pH}$ 7.2) three times. Subsequently, the slides were treated with $0.1 \mathrm{M}$ triethanolamine $(\mathrm{pH}$ 8.0)/acetic anhydride, 400:1 (vol:vol) stirring for $10 \mathrm{~min}$ utes at room temperature. Finally, the sections were rinsed in $2 \times$ SSC for 5 minutes and dehydrated through graded alcohols before letting them air dry. $\left[{ }^{35} \mathrm{~S}\right]$-labeled probes were then applied diluting $3-5 \times 10^{6} \mathrm{cpm}$ in $400 \mu \mathrm{l}$ per slide of hybridization buffer (50\% deionized formamide, $3 \times$ SSC, $1 \times$ Denhardt's solution $(0.02 \%$ polyvinyl pyrrolidone, $0.02 \%$ Ficoll, $0.02 \%$ bovine serum albumin), $2 \%$ yeast tRNA $(10 \mathrm{mg} / \mathrm{ml}), 50 \mathrm{mM}$ sodium phosphate, and $10 \%$ dextran sulfate in sterile water, $\mathrm{pH}$ 7.4). Slides were covered with glass coverslips and placed in humid chambers containing an atmosphere saturated with $50 \%$ formamide at $55^{\circ} \mathrm{C}$ overnight. After 16 hours of hybridization, coverslips were removed and sections were washed three times in $2 \times \mathrm{SSC}$ at room temperature, immersed in RNAse A (200 mg/ml in $10 \mathrm{mM}$ Tris, $0.5 \mathrm{M} \mathrm{NaCl}$, pH 8.0) for 30 minutes at $37^{\circ} \mathrm{C}$, and then washed through descending concentrations of SSC to a final stringency of $0.1 \times$ SSC at $60^{\circ} \mathrm{C}$ for 2 hours. Finally, the sections were dehydrated in graded ethanol solutions, allowed to air dry, and placed in X-ray cassettes to be exposed to Kodak BIOMAX MR film (Kodak, Rochester, NY) for 7-10 days. Control slides were used to assess the specificity of each riboprobe, running "sense-strand" labeled sections in parallel with those labeled with "antisense-strand" probes.

\section{Cell-level autoradiography}

After developing the films, sections were dipped in Kodak NTB-2 emulsion diluted 1:1 with sterile water, 
TABLE 2. Relative Expression of Transcripts Encoding AMPA Subunits and PSD Proteins

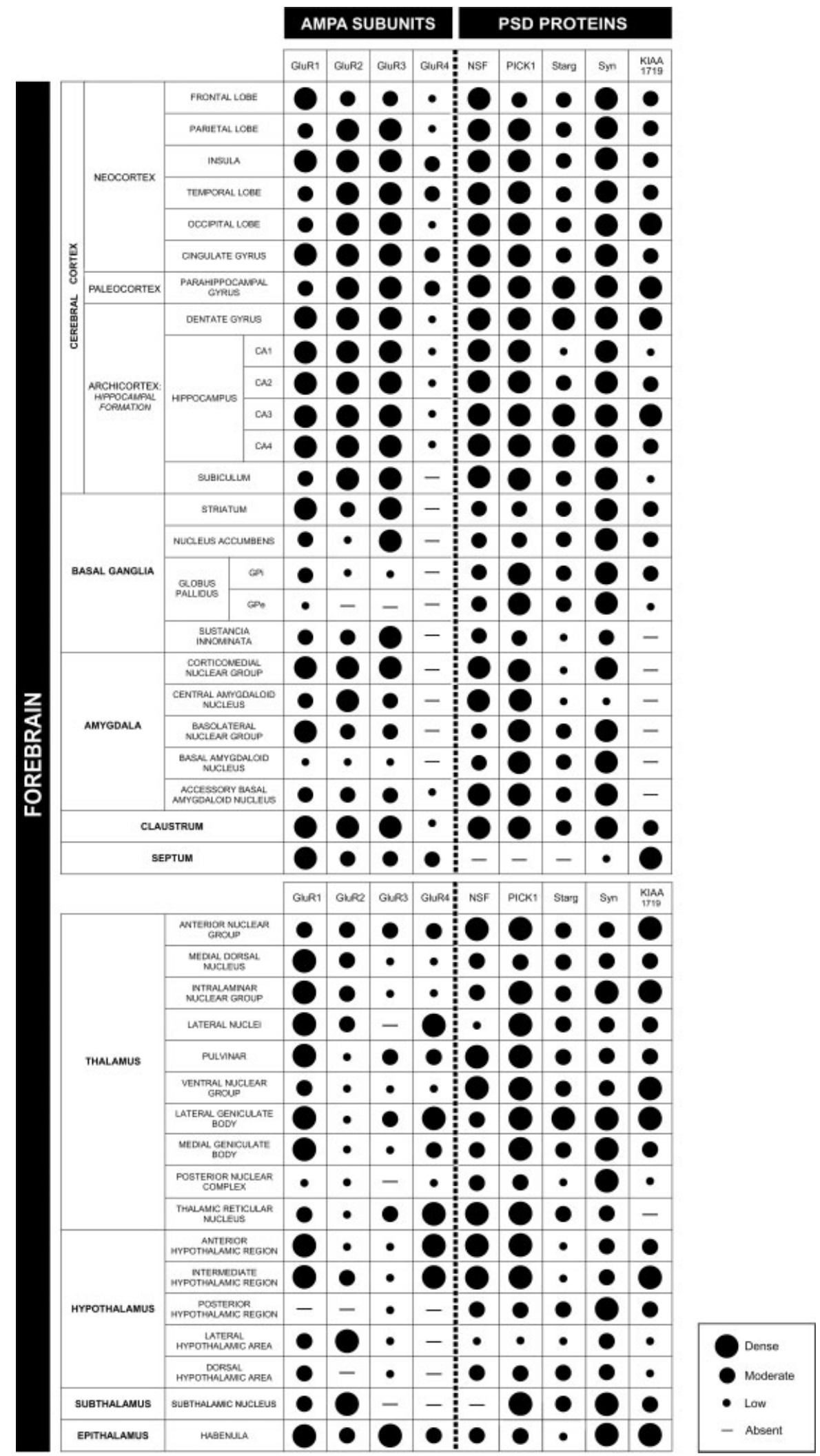


TABLE 2. (continued)
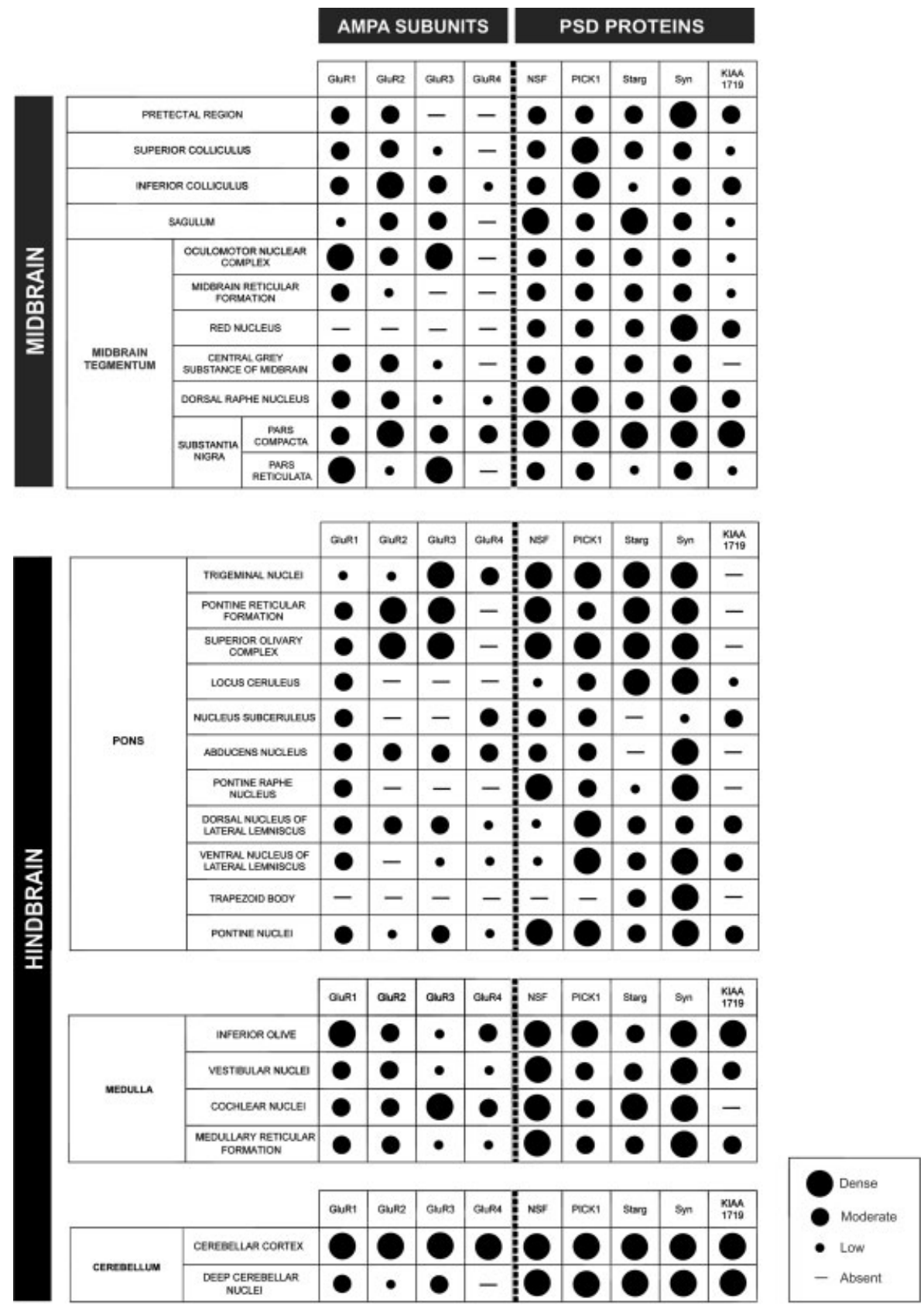

air-dried, stored in individual slide boxes, and exposed for $4-6$ weeks at $4^{\circ} \mathrm{C}$. Test slides containing hybridized tissue with the same probes were also emulsion-dipped on the same day. Test slides were developed at weekly intervals to determine optimal exposure time for the primary slides. After 4-5 weeks, all slides were developed in Kodak D19 developer for 2 minutes, washed in distilled water for 30 seconds, and fixed in Kodak Rapid Fix for 3 minutes. Following washing in deionized water for 10 minutes, the sections were counterstained using the Nissl technique, dehydrated in graded alcohols, cleared in xylene, and coverslipped in Permount.

\section{Image analysis}

Images were acquired by digitizing film images using a CCD camera with NIH Image software, v. 1.61. Photographs from emulsion-dipped sections were taken with a Zeiss Axioskop microscope using bright and/or darkfield. Macroscopic images were individually compared to plates and diagrams from two macaque atlases (Martin and Bowden, 2000; Paxinos et al., 2000) for identification of structures. Schematic anatomical diagrams in Figures 2-9 are modified from those of Martin and Bowden (2000). Relative level of transcript expression in each specific 
region of interest was estimated based by grayscale values on a scale of 0 to +3 . Expression in the pontine nuclei provides an example of our estimates of relative transcript levels (compare Fig. 7 and Table 2). For the probes used in this study, we assigned the highest level of mRNA expression $(+3)$ to structures with a grayscale value similar to that of NSF (Fig. 7F), PICK1, or syntenin (Fig. 7G,I) in the pontine nuclei. Structures with moderate levels of expression $(+2)$ were those with label intensity comparable to that of GluR1, GluR3, or stargazin (Fig. 7B,D,H) mRNA in the pontine nuclei. Finally, the signal intensity rated as low $(+1)$ was given to the structures with labeling similar to that of GluR2 and GluR4 (Fig. 7C,E) in the pontine nuclei. No expression (0) was assigned when expression levels were comparable to what was observed in areas of white matter.

Photographic processing was made using Adobe PhotoShop 5.5 and the final illustrations were composed using standard methods (Adobe Illustrator 10.0, San Jose, CA) without altering the primary data.

\section{RESULTS}

The distributions of the transcripts encoding all four AMPA receptor subunits (GluR1, GluR2, GluR3, and GluR4) were heterogeneous, showing differential regional distribution and different levels of expression throughout numerous structures in the brain, with GluR1 being the most ubiquitous subunit. The transcripts encoding the associated postsynaptic proteins were widely distributed in the brain, but surprisingly, those proteins known to interact with specific AMPA subunits in vitro did not match exclusively with those subunits (Table 2). Parallel experiments using "sense strand" riboprobes produced minimal labeling in control sections.

\section{Telencephalon}

Neocortex. In the cerebral cortex the AMPA subunits GluR1, GluR2, and GluR3 were widely distributed. In general, the expression of GluR1, GluR2, and GluR3 subunit transcripts were expressed in all six cortical layers except the molecular layer I, but the density of expression varied across cortical laminae, with a specific expression pattern for each receptor subunit. GluR1 and GluR2 were present in all layers, with GluR1 more abundant in layers Va and VI (Fig. 1B). GluR2 had a different pattern of expression labeling with high expression in layers II-III and VI, but weaker in layer V (Fig. 1C). GluR3 was practically absent in layer IVb, very low in layer VIa, but had stronger labeling in layer IVa (Fig. 1D). The overall density of GluR4 signal was very low throughout the cortex, primarily seen only in the superficial layers, especially in the insular and perirhinal cortices (Figs. 3-7). Light microscopic observation of emulsion-dipped slides confirmed the pattern of laminar labeling shown in the autoradiographic films, revealing specific labeling of both pyramidal and stellate neurons as well as small interneurons (Fig. $11 \mathrm{~F})$.

The AMPA-associated proteins, PICK1 and syntenin, also showed differential laminar distribution. While PICK1 was expressed more intensely in layers V and VI (Fig. 1G), syntenin was expressed in two intense isodense bands, corresponding to layer IV and the deep aspect of layer V-superficial layer VI; very weak labeling was observed in the superficial sublamina of layer V (Fig. 1I).
Interestingly, the distribution of PICK1 was similar to that of GluR2 (cf. Fig. 1C,G), while syntenin expression, although more dense, had a pattern quite similar to GluR3. The other two PSD proteins, NSF and stargazin, both had specific distributions in the cortex. NSF was expressed preferentially in layers $\mathrm{V}$ and deep layer VI, while stargazin was localized in all cortical layers, showing a higher expression in layer VI (Fig. 1F,H). Finally, the protein KIAA1719 was expressed in layers II, V, and deep VI (Fig. 10A). The emulsion dipped slides showed that these PSD proteins had the same ubiquitous neuronal distribution in the cortex as the AMPA subunits, being present in both pyramidal and nonpyramidal cells and in small interneurons.

Hippocampal formation. GluR4 was the only AMPA receptor subunit virtually absent from the hippocampal formation (HiF) and the dentate gyrus (DG), while the other AMPA receptor subunits had very high expression levels in those structures (Figs. 4-6E). Both the pyramidal layer of CA1-4 and the granule cells of the DG had high levels of GluR1-3 expression. The two pyramidal sublayers of CA1 were clearly delineated for those three subunits (Figs. 4B,D, 5B,D). In the subiculum (Sub), the most abundant AMPA receptor subunit was GluR3 (Figs. 5D, 6D), followed by GluR1 (Figs. 5B, 6B). All of the PSD protein transcripts were expressed in the hippocampus, with dense expression in the dentate gyrus. NSF and PICK1 were expressed throughout the hippocampal formation and NSF was more abundant. NSF and syntenin were both expressed in the presubiculum, but primarily medially at its connection with the posterior parahippocampal gyrus. NSF and syntenin had very low levels of expression in the deepest layers of the presubiculum, thus clearly delineating the transition from the presubiculum to the cortex, suddenly disappearing at the fusiform gyrus (Figs. 5F,I, 6F,I). Stargazin had a different pattern of expression, with very high expression in the dentate gyrus, CA3 and CA4, very low expression in CA1 and CA2, and then increasing again medially at the presubiculum (Figs. 5H, 6H, 11C,D).

Striatum. As in the hippocampus, the only AMPA subunit transcript absent in the basal ganglia was GluR4 (Figs. 2-4E). In the striatum, both the caudate (CA) and putamen $(\mathrm{Pu})$ had high levels of expression for GluR1 (Figs. 2-4B) and GluR3 (Figs. 2-4D), and moderate levels for GluR2 (Figs. 2-4C). All of the PSD proteins were expressed in both putamen and caudate nucleus. The highest expression levels were seen for NSF, PICK1, and syntenin (Figs. 2-4). Stargazin and KIAA1719 expression was very low, especially at more rostral levels (Figs. $2 \mathrm{H}$, 10B-D). None of these transcripts were differentially expressed in the striosomal and matrix compartments of the striatum.

In the nucleus accumbens (Acc) the highest level of expression was for the GluR3 subunit, followed by GluR1 with moderate levels, and finally by GluR2 with the least expression. As in the striatum, we could not observe any expression of the GluR4 subunit in the Acc. However, all of the PSD proteins were present in this nucleus. While syntenin had a high level of expression, the rest of the proteins studied showed moderate expression in this nucleus. We were unable to see differential expression of any of the proteins between the shell and the core of the Acc.

Globus pallidus. The highest level of expression for the AMPA subunits in the globus pallidus (GP) was for the 

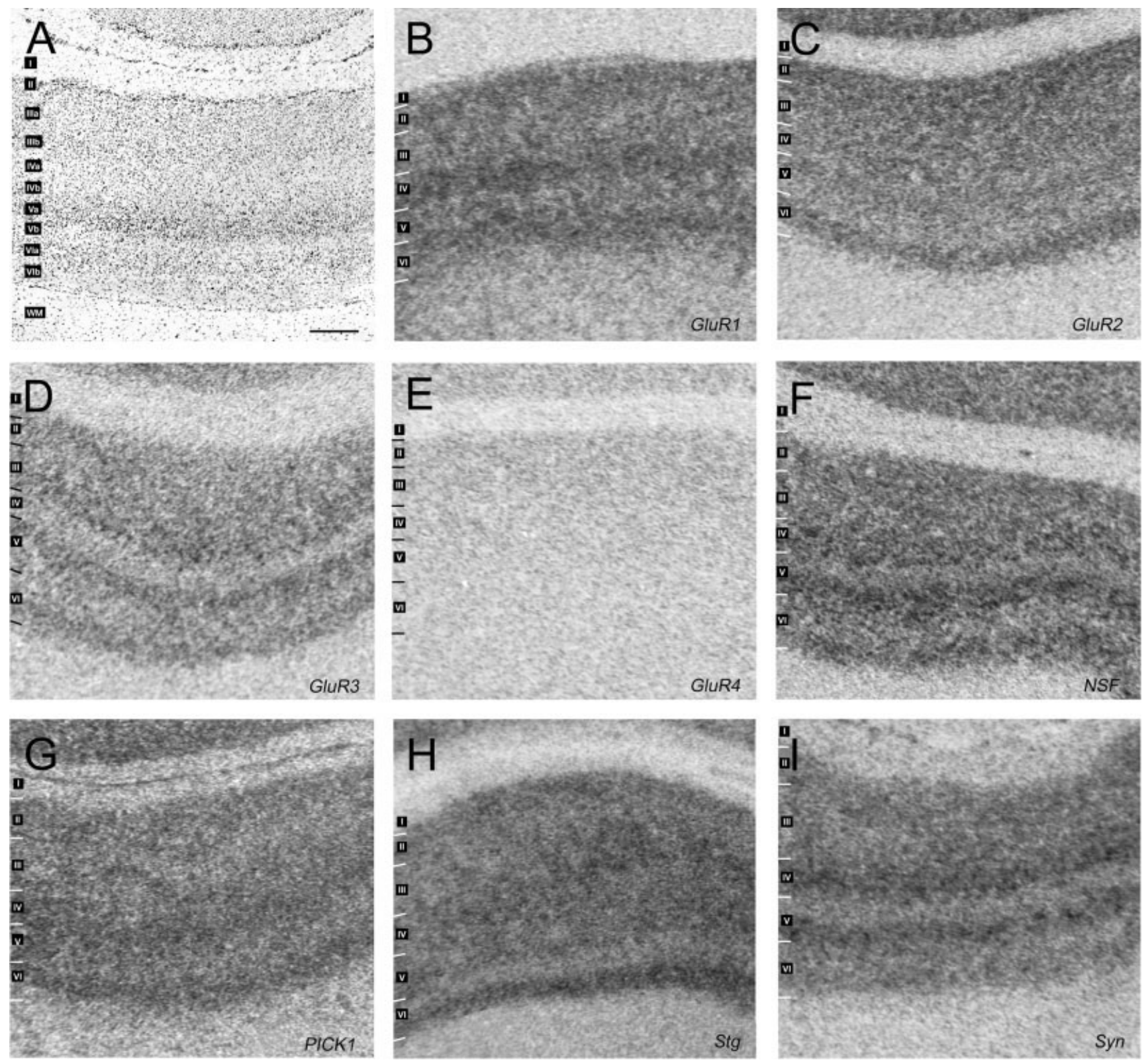

Fig. 1. Nissl-stained (A) and in situ hybridization of sections of the neocortex (primary visual area 17), showing the laminar distribution of the expression of: (B-E) the AMPA subunits (GluR1-GluR4), and (F-I) PSD related proteins (NSF, PICK1, stargazin (Stg), and syntenin (Syn)). Scale bar $=500 \mu \mathrm{m}$.

GluR1 subunit, present in both the medial or internal segment (Gpi) and the lateral or external segment (Gpe) (Fig. 3B). GluR3 signal was present only in the Gpe (Fig. 3D); GluR2 was also restricted to Gpe, but at lower levels than seen for GluR3 and concentrated in the ventral portion (Fig. 3C). All of the PSD proteins were expressed in both segments of the globus pallidus. While NSF showed similar expression in both Gpi and Gpe, PICK1 was enriched in Gpe (Fig. 3G), and syntenin was more abundant in Gpi (Figs. 3I, 12C,D). Stargazin, with a very low expression level, was preferentially expressed in Gpi, especially more caudally (Fig. 3H). Finally, KIAA1719 mRNA was expressed in both segments, but at very low levels (Fig. 10D).

Substantia innominata. Although GluR4 expression was not found in the substantia innominata (SI), the rest of AMPA receptors, GluR1, GluR2, and GluR3, were present in this nucleus (Fig. 3B-E). While the GluR3 subunit was highly expressed in SI (Fig. 3D), GluR1 and GluR2 had only moderate levels of expression (Fig. 3B,C). Among the PSD proteins, NSF, PICK1, and syntenin were moderately expressed (Fig. 3F,G,I), while stargazin had a low level of expression (Fig. 3H), and KIAA1719 was not expressed at all (Fig. 10). 

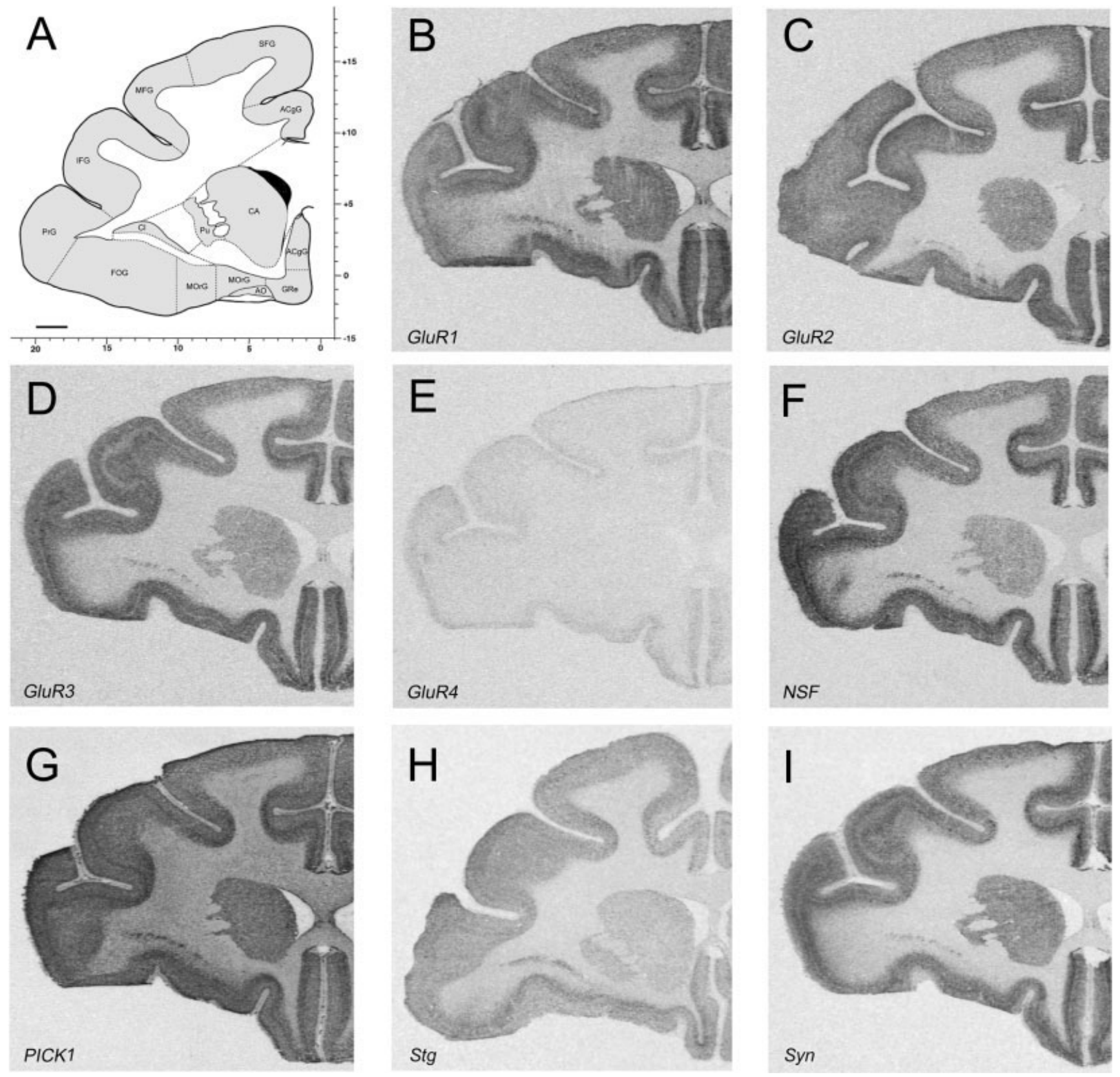

Fig. 2. In situ hybridization of coronal sections at $6 \mathrm{~mm}$ anterior (ac $+6.0 \mathrm{~mm}$ ) to the anterior commissure, including the prefrontal cortex and the anterior striatum. A: Corresponding anatomical level.

B-E: Transcript expression for the AMPA subunits (GluR1-GluR4). F-I: Transcript expression of PSD related proteins (NSF, PICK1, stargazin (Stg), and syntenin (Syn)). Scale bar $=5 \mathrm{~mm}$.

Amygdala. All AMPA receptor subunits, except GluR4, were expressed in the amygdala, but with differential expression across discrete nuclei. Interestingly, although the levels of expression of all subunits were high in all amygdaloid nuclei, GluR1 was particularly enriched in the lateral nucleus (LA) (Fig. 3B), while GluR3 was highly expressed in the magnocellular division of the basal nucleus of the amygdala (BA) (Fig. 3D). GluR1 and GluR2 were both expressed moderately in the anterior cortical nucleus $(\mathrm{CoA})$ and central nucleus $(\mathrm{CeA})$ of the amygdala (Fig. 3B,C), in contrast to less expression of GluR3 in those nuclei (Fig. 3D), but relatively higher expression in the accessory basal nucleus (ABA). In the amygdala, all of the PSD proteins studied were expressed in all nuclei, but also differed in expression level. Stargazin had very low expression in LA, but was somewhat more abundant in $\mathrm{BA}$, medial (MeA), ABA, and in the paramygdaloid area (PA) (Fig. 3H). PICK1 was homogeneously expressed at moderate levels in all the amygdaloid nuclei (Fig. 3G). On the other hand, NSF and syntenin had heterogeneous expression in the dorsal part of BA and differential patterns of expression in the MeA (Fig. 3F,I), a pattern of 

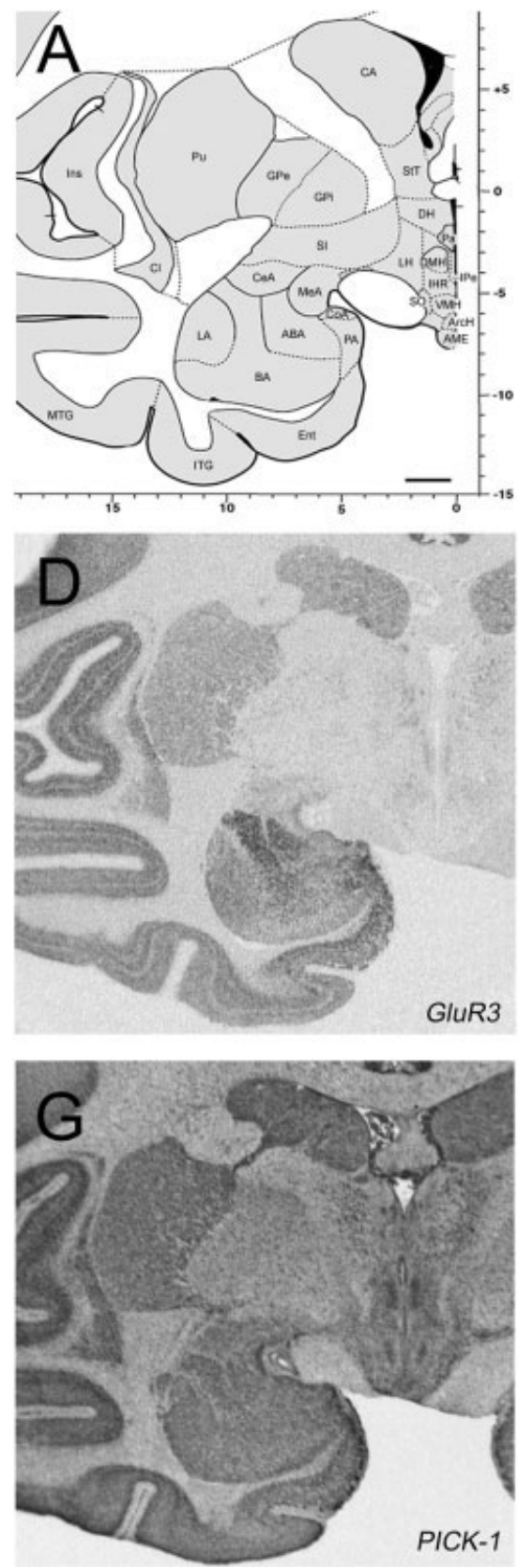
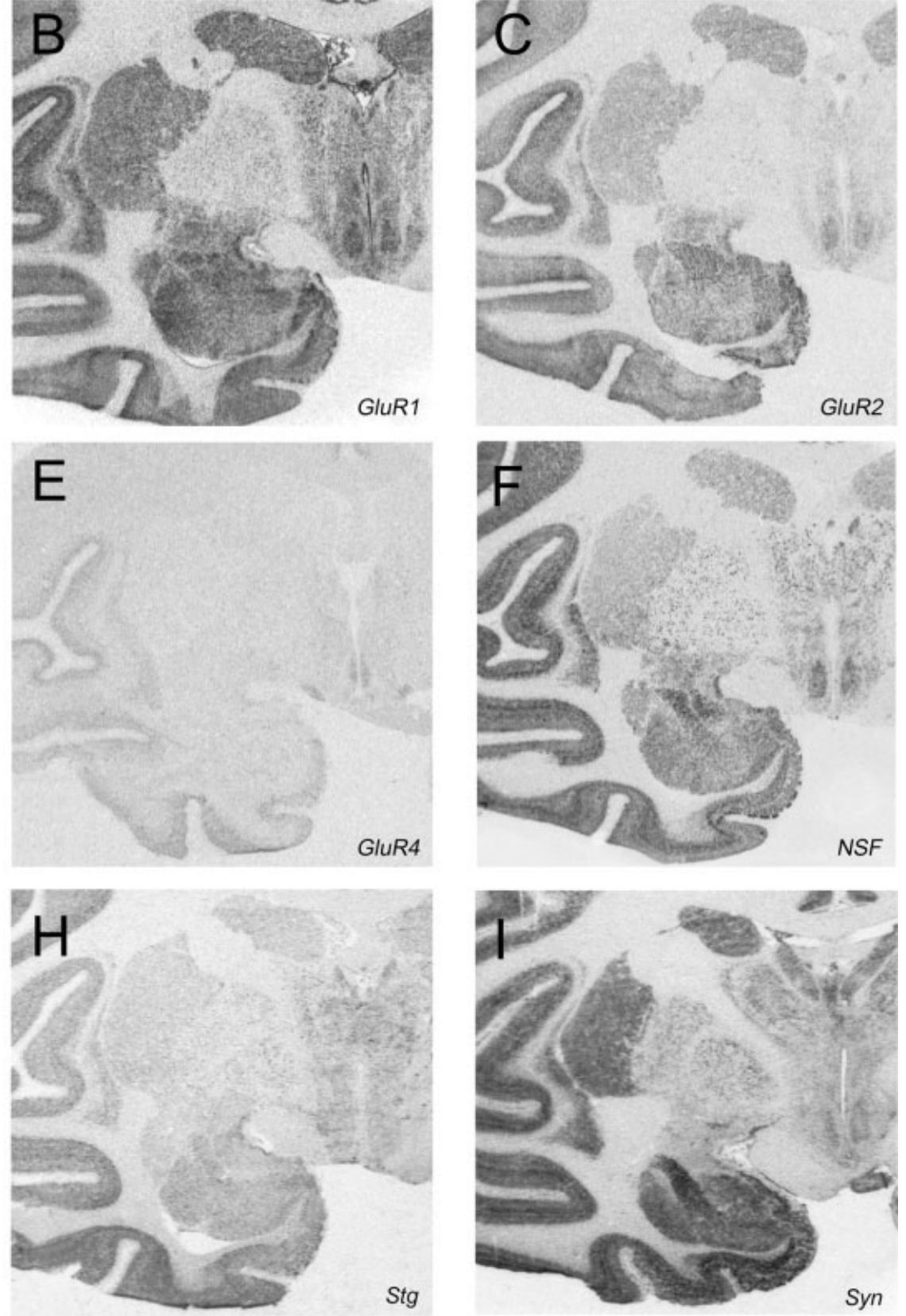

Fig. 3. In situ hybridization coronal sections at $1 \mathrm{~mm}$ posterior (ac $-1.0 \mathrm{~mm}$ ) to the anterior commissure, showing transcript expression in the claustrum, striatum, amygdala, and hypothalamus. A: Corresponding anatomical level. B-E: Transcript expression for the AMPA subunits (GluR1-GluR4). F-I: Transcript expression of PSD related proteins (NSF, PICK1, stargazin (Stg), and syntenin (Syn)). Scale bar $=5 \mathrm{~mm}$. expression in the amygdala very similar to that seen for GluR3 (Fig. 3D).

Claustrum. All AMPA receptor subunits were expressed in the claustrum. GluR1 showed the highest level (Figs. 2-4B), followed by GluR2 and GluR3 (Figs. 2-4C,D). GluR1-GluR3 probes produced a lateromedial pattern of increasing expression in the ventral portion of the nucleus, especially noticeable for GluR1 and GluR3 (Fig. 3B,D). GluR4 had the lowest gradient of expression pattern in the claustrum (Figs. 2-4E). Similar results were observed for the PSD proteins. Stargazin showed the lowest mRNA expression in the claustrum (Figs. 2-4H), while NSF, PICK1, and syntenin had an intensity and pattern of expression similar to that of GluR1.

\section{Diencephalon}

Thalamus. In general, GluR1 had the highest expression of all the AMPA receptor subunits in the thalamus (Figs. 4-6). GluR1 was present in almost all thalamic nuclei, with relative enrichment in the reticular and me- 

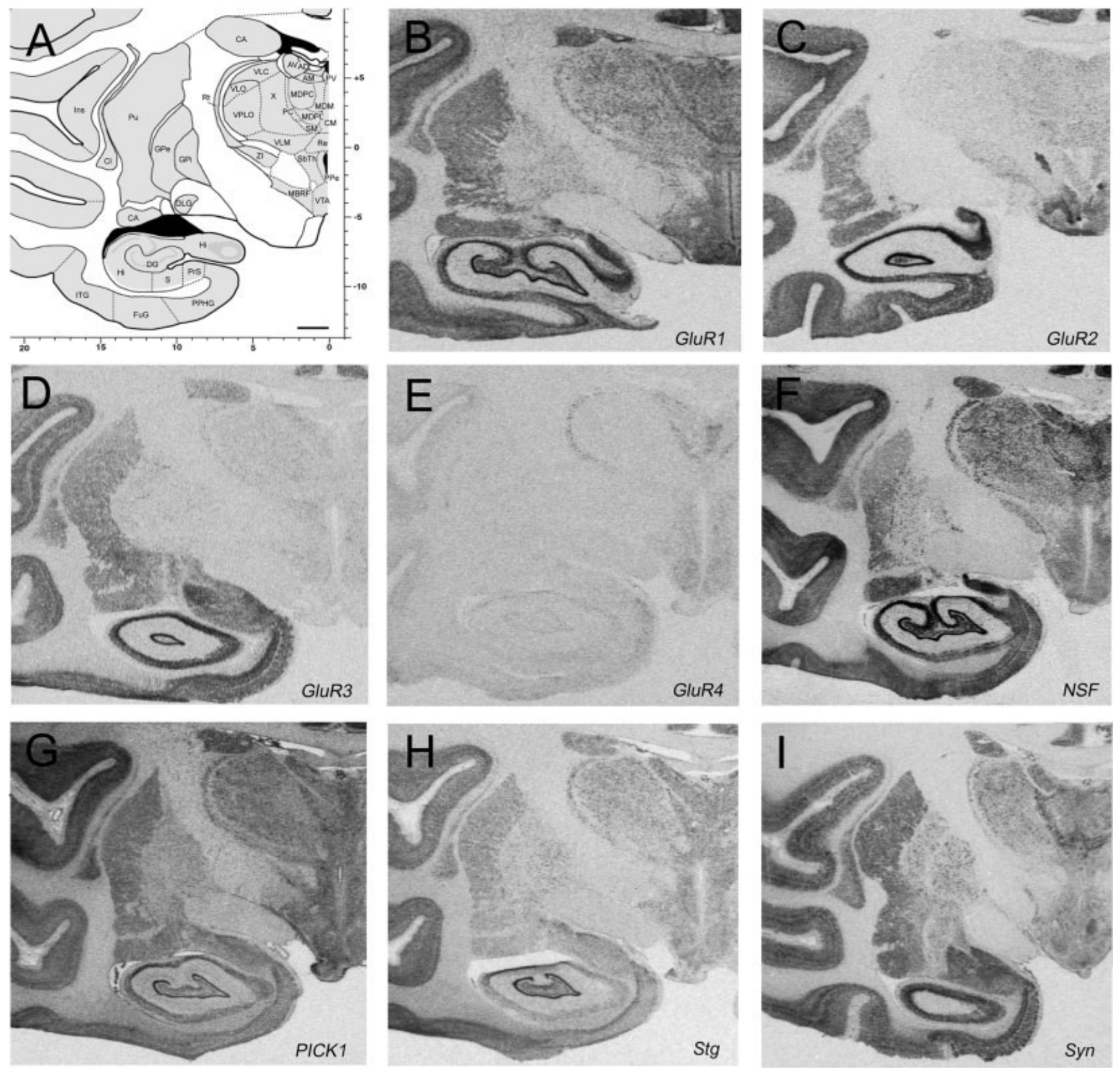

Fig. 4. In situ hybridization coronal sections at $6 \mathrm{~mm}$ posterior (ac $-6.0 \mathrm{~mm}$ ) to the anterior commissure, showing transcript expression in the anterior striatum, thalamus, hypothalamus, and hippocampus. A: Corresponding anatomical level. B-E: Transcript expression for the AMPA subunits (GluR1-GluR4). F-I: Transcript expression of PSD related proteins (NSF, PICK1, stargazin (Stg), and syntenin $($ Syn $)$ ). Scale bar $=5 \mathrm{~mm}$. dial dorsal nuclei and the intralaminar nuclear group (Fig. 4B). Moderate expression of this subunit was also observed in the anterior, lateral, and ventral nuclear groups (Figs. 4B, 5B). In contrast, GluR2 and GluR3 transcripts could be observed in the reticular nucleus, but both were expressed at much lower levels in other thalamic nuclei (Figs. 4-6C,D). GluR4 was abundant in the reticular nucleus and intralaminar nuclear group, contrasting with extremely low levels of expression in all other thalamic nuclei (Figs. 4-6E). In the metathalamus, GluR2,
GluR3, and GluR4 also had low to moderate levels of expression in the dorsal nucleus of the lateral geniculate body, pulvinar nuclei, and medial geniculate body. GluR1 had higher expression levels in these nuclei (Figs. 5, 6).

The PSD proteins had specific patterns of distribution in the thalamus. Similar to the four AMPA receptor subunits, all of the PSD proteins were expressed in the reticular nucleus of the thalamus (Figs. 4-6). NSF and syntenin had very high expression in the intralaminar nuclear complex (Fig. 4F,I), while PICK1 and stargazin both had 

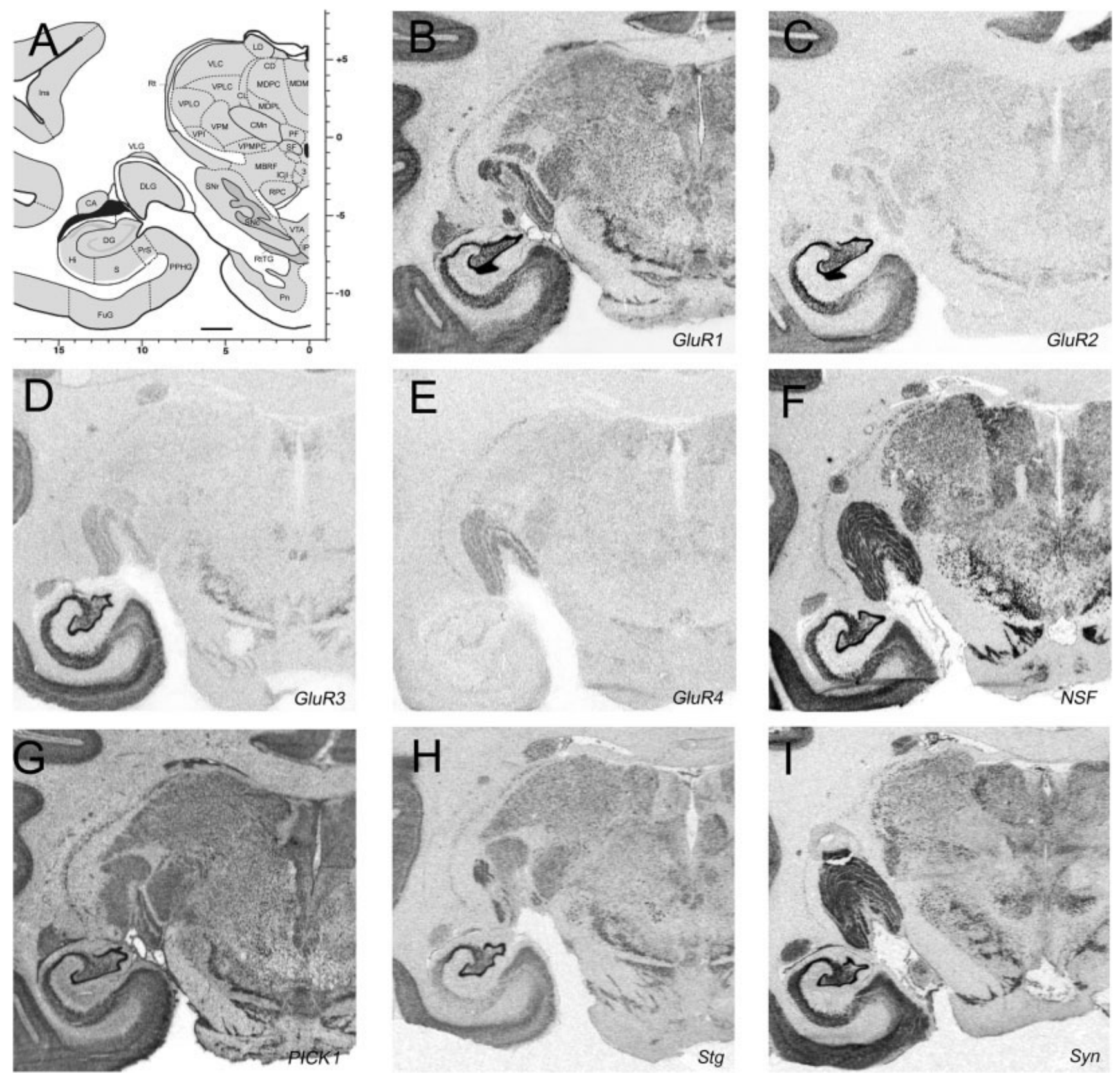

Fig. 5. In situ hybridization of coronal sections at $8 \mathrm{~mm}$ posterior (ac $-8.0 \mathrm{~mm}$ ) to the anterior commissure, showing transcript expression in thalamus, hippocampus, and substantia nigra. A: Corresponding anatomical level. B-E: Transcript expression for the AMPA sub-

units (GluR1-GluR4). F-I: Transcript expression of PSD related proteins (NSF, PICK1, stargazin (Stg), and syntenin (Syn)). Scale $\mathrm{bar}=5 \mathrm{~mm}$.

moderate expression levels (Fig. 4G,H). NSF was also very abundant in the ventral and anterior nuclei (Figs. 4F, 5F), followed in density by PICK1 and KIAA1719 (Figs. 4G, $5 \mathrm{G}, 10 \mathrm{D}-\mathrm{F})$, and finally, stargazin and syntenin with lower levels of expression (Figs. 4H,I, 5H,I). All of these proteins were highly expressed in the lateral nuclear group, especially in the pulvinar nuclei (Figs. 6, 10E). In the metathalamus, syntenin was most abundant in the medial geniculate body, especially in its ventral nucleus (Fig. 6I). The other proteins were also expressed in this

nucleus, but their relative expression was lower than that of syntenin (Figs. 6F-H, 10E). Finally, all of the PSD proteins were highly expressed in the lateral geniculate body, in both dorsal and ventral nuclei (Figs. 5, 6, 10E-F). Overall, the PSD proteins were expressed at higher relative levels than most of the AMPA subunits, with the exception of the abundant GluR1 transcript.

Hypothalamus. All of the molecules studied were observed in one or more nuclei of the hypothalamus. GluR1 was the AMPA subunit with highest expression in this 

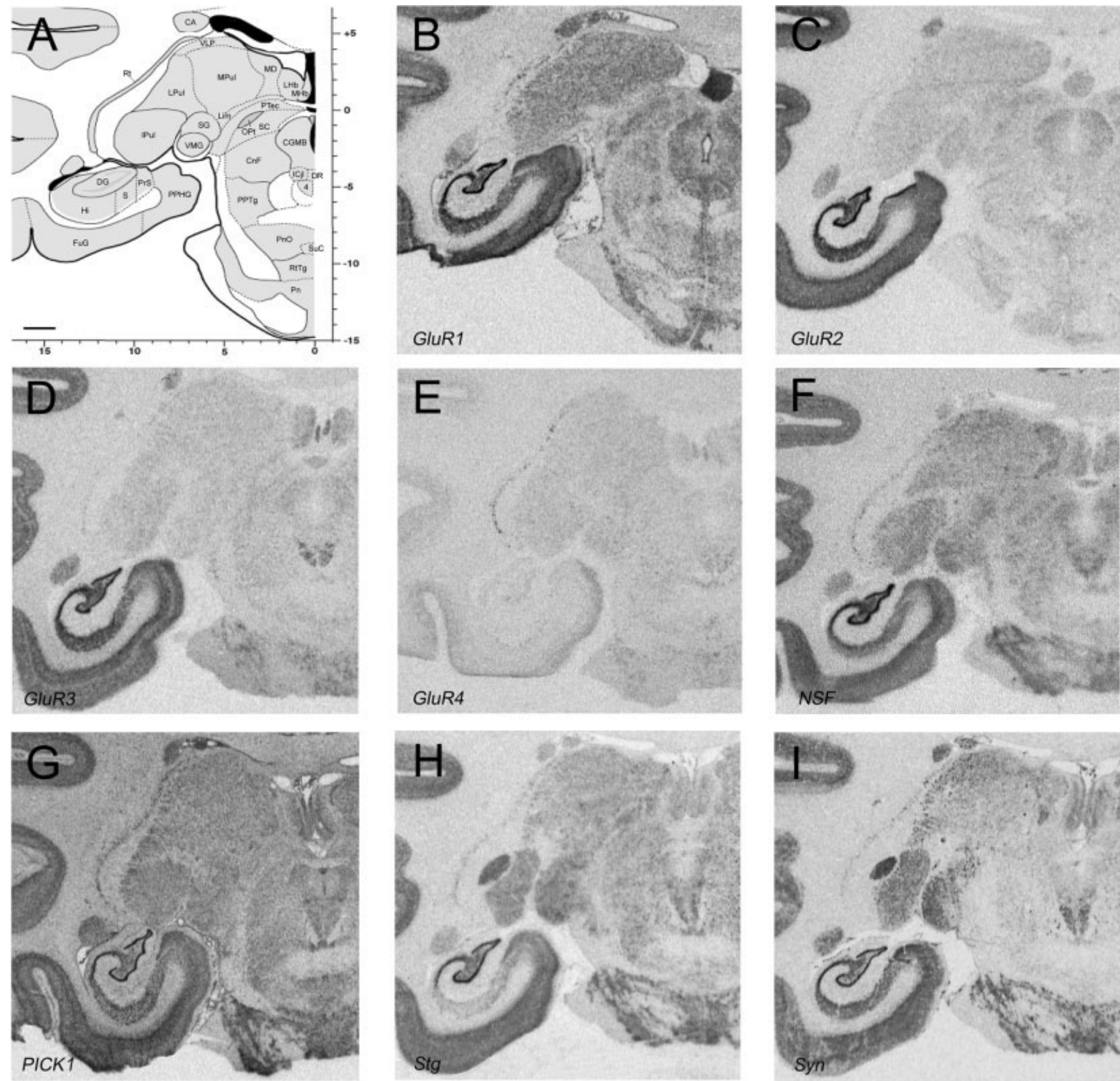

Fig. 6. In situ hybridization of sections at $12 \mathrm{~mm}$ posterior (ac $-12.0 \mathrm{~mm}$ ) to the anterior commissure, showing transcript expression in the lateral thalamic nuclei, medial geniculate body, reticular nucleus, and the hippocampus. A: Corresponding anatomical level. B-E:

Transcript expression for the AMPA subunits (GluR1-GluR4). F-I: Transcript expression of PSD related proteins (NSF, PICK1, stargazin (Stg), and syntenin (Syn)). Scale bar $=5 \mathrm{~mm}$.

structure (Figs. 3B, 4B). It had high expression in the intermediate hypothalamic region, with very high expression in the ventromedial nucleus (VMH). The lateral and the anterior hypothalamic regions also showed expression of this subunit. GluR2 mRNA expression was very high in the anterior hypothalamic region, but expression in the lateral and the intermediate hypothalamic regions were much lower than seen for GluR1 (except VMH, where the signal density was moderate) (Figs. 3C, 4C). GluR3 and GluR4 were expressed at much lower levels in the hypo-

thalamus. GluR3 had low to moderate expression levels in the pariventricular nucleus of the anterior hypothalamic region $(\mathrm{Pa})$ (Fig. 3D), and GluR4 in the tuberomammillary nucleus of the lateral hypothalamic area and in the intermediate periventricular nucleus (Fig. 3E). The VMH nucleus in the intermediate hypothalamic region had very high expression of all the PSD proteins studied except stargazin, which was expressed rather homogeneously and at moderate levels in all of the regions of the hypothalamus. PICK1, the PSD protein with the highest level 

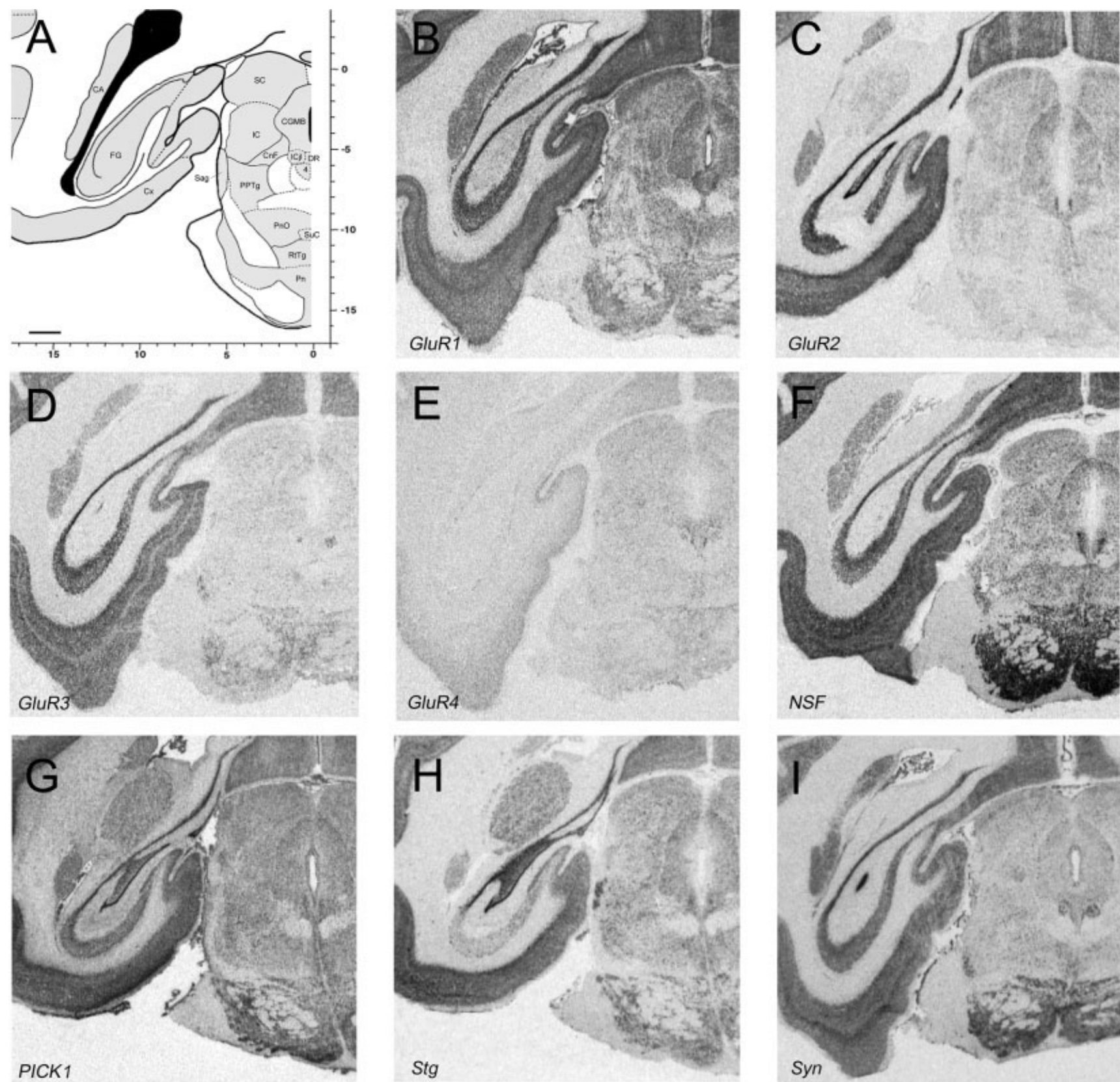

Fig. 7. In situ hybridization of sections at $14 \mathrm{~mm}$ posterior (ac $-14.0 \mathrm{~mm}$ ) to the anterior commissure, showing transcript expression in the fusiform cortical gyrus, superior colliculus, dorsal raphe, sagulum, and pontine nuclei. A: Corresponding anatomical level. B-E:

Transcript expression for the AMPA subunits (GluR1-GluR4). F-I: Transcript expression of PSD related proteins (NSF, PICK1, stargazin (Stg), and syntenin (Syn)). Scale bar $=5 \mathrm{~mm}$.

of expression in the hypothalamus, and KIAA1719 both had high expression levels in Pa (Figs. 3G, 10C).

Subthalamus. Only two of the four AMPA subunits were expressed in the subthalamic nucleus (SbTh) and zona incerta (Fig. 4B-E). GluR1 had moderate expression, while GluR2 was highly expressed in the subthalamic nucleus (Fig. 4B,C). Interestingly, all of the PSD proteins, including KIAA1719, were expressed in the subthalamic nucleus. The densest expression was observed for NSF, PICK1, and syntenin (Fig. 4F, G,I); stargazin (Fig. 4H) and
KIAA1719 (Fig. 10D) showed only moderate to low expression in this nucleus.

\section{Midbrain tectum}

Superior colliculus. GluR1 was the most abundantly expressed AMPA subunit in the superior colliculus (SC). This subunit was especially prominent in superficial layers, including both the superficial gray layer and the stratum opticum (Fig. 7B). The same pattern of expression for GluR2 mRNA was observed, although this transcript was 

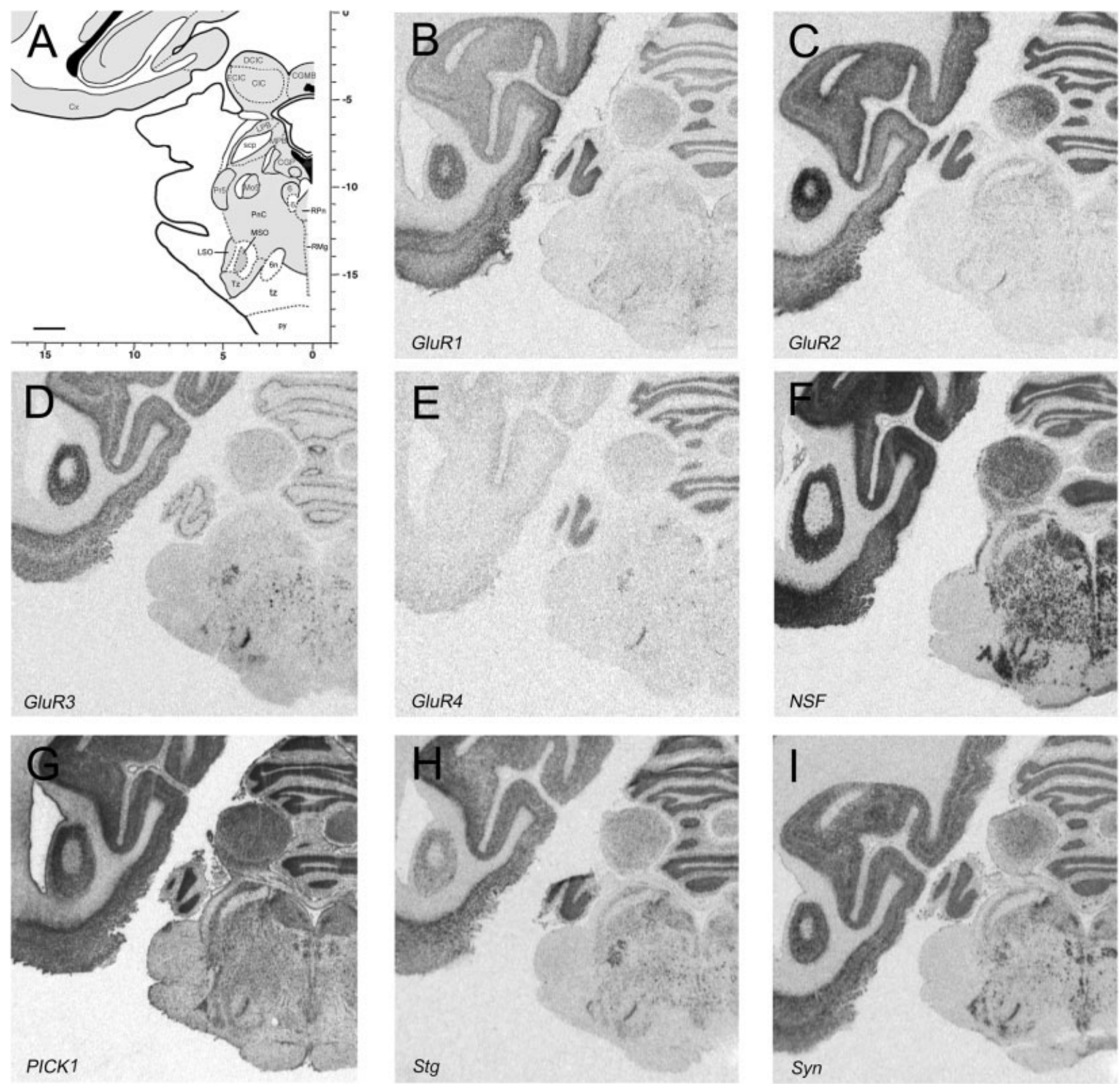

Fig. 8. In situ hybridization of sections at $16.5 \mathrm{~mm}$ posterior (ac $-16.5 \mathrm{~mm}$ ) to the anterior commissure, including transcript expression in the inferior colliculus, basal pons, and rostral pole of the cerebellum. A: Corresponding anatomical level. B-E: Transcript ex-

pression for the AMPA subunits (GluR1-GluR4). F-I: Transcript expression of PSD related proteins (NSF, PICK1, stargazin (Stg), and syntenin (Syn)). Scale bar $=5 \mathrm{~mm}$.

expressed at lower levels than GluR1 (Fig. 7C). Neither GluR3 nor GluR4 were expressed to any significant extent (Fig. 7D,E). The four AMPA-related intracellular proteins studied were highly expressed in this nucleus, exhibiting a homogeneous pattern across all collicular layers but with a higher level of expression in the superficial gray layer for NSF, PICK1, and stargazin (Fig. 7F-H). Interestingly, the pattern of expression of syntenin was slightly different, as it had denser expression in the intermediate layer (Fig. 7I).
Inferior colliculus. In the inferior colliculus (IC), the most highly expressed AMPA subunit was GluR2, particularly in the dorsal cortex of this nucleus (Fig. 8C). GluR1 and GluR3 were expressed at lower levels in the IC (Fig. $8 \mathrm{~B}, \mathrm{D})$ and GluR4 mRNA could be barely detected (Fig. $8 \mathrm{E})$.

In contrast, the PSD proteins exhibited high levels of expression in the central nucleus and both the external and dorsal cortex of the IC. NSF and PICK1 had the highest levels of expression, but these two proteins dif- 

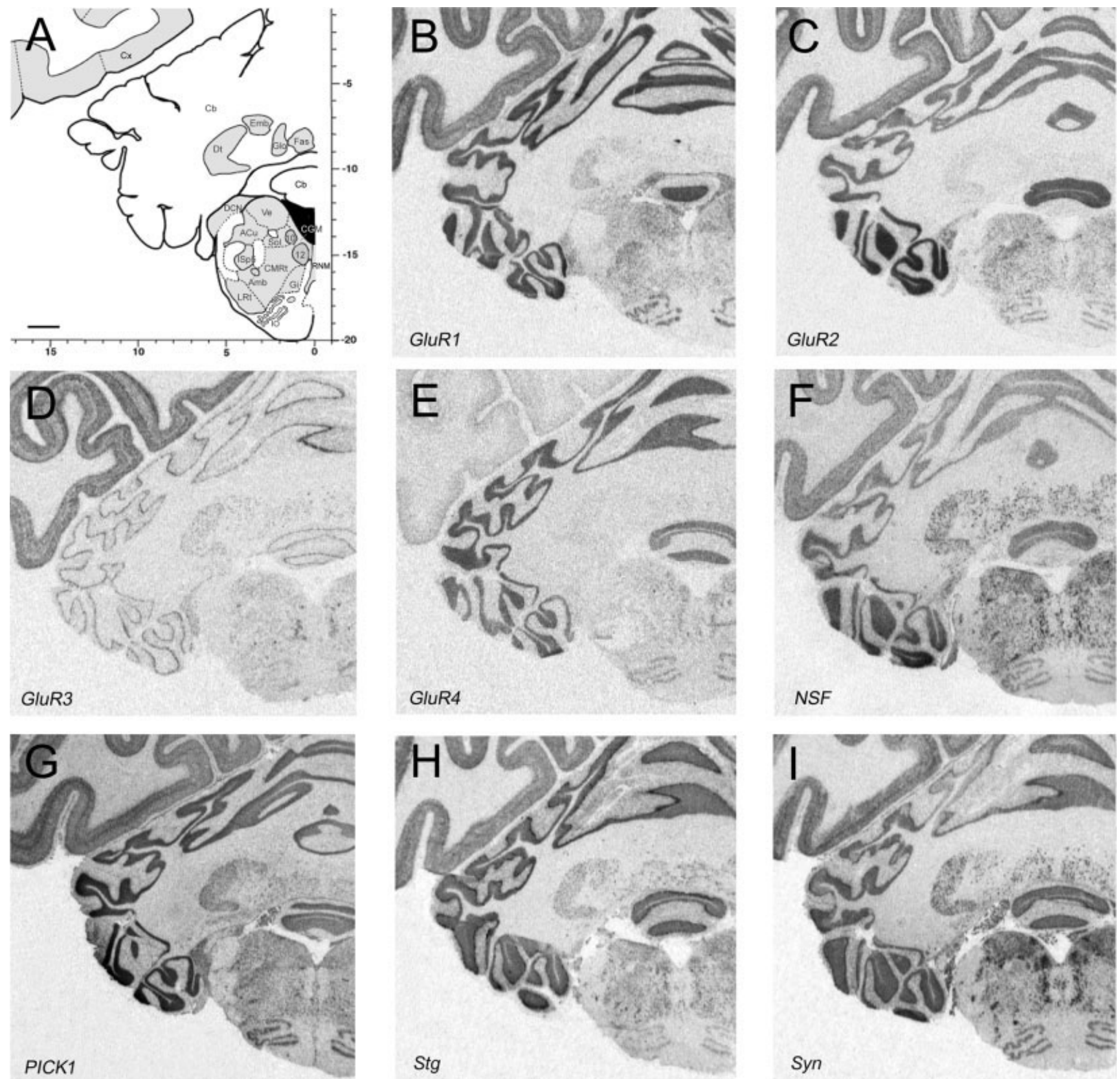

Fig. 9. In situ hybridization of sections at $21.0 \mathrm{~mm}$ posterior (ac $-21.0 \mathrm{~mm}$ ) to the anterior commissure, showing transcript expression in the medulla oblongata and cerebellum. A: Corresponding anatom-

ical level. B-E: Transcript expression for the AMPA subunits (GluR1GluR4). F-I: Transcripts expression of PSD related proteins (NSF, PICK1, stargazin (Stg), and syntenin (Syn)). Scale bar $=5 \mathrm{~mm}$.

fered in their regional expression in the nucleus; NSF was more abundant in the braquium of the IC (Fig. 8F), while PICK1 was expressed more intensely in the dorsal lemniscus beneath the IC (Fig. 8G). Stargazin and syntenin had lower levels of expression in this nucleus, differing in the density of expression in the central nucleus, where syntenin (Fig. 8I) was concentrated, while stargazin was homogeneously distributed throughout the entire structure (Fig. 8H).

Sagulum. Ventral to the IC, in the nucleus sagulum, the four AMPA subunits were expressed at intermediate
(GluR2 and GluR3) or very low (GluR1 and GluR4) levels. NSF, PICK1, stargazin, and syntenin were all highly expressed in this nucleus (Figs. 6F-I, 7F-I), contrasting with the low expression of KIAA1719 (Fig. 10G). The inferior olivary complex, on the contrary, showed a matched pattern of expression between receptor subunits and their related PSD proteins (Fig. 9).

\section{Midbrain tegmentum}

Red nucleus. Among the four AMPA receptor subunits, only GluR1 was expressed in the red nucleus at 

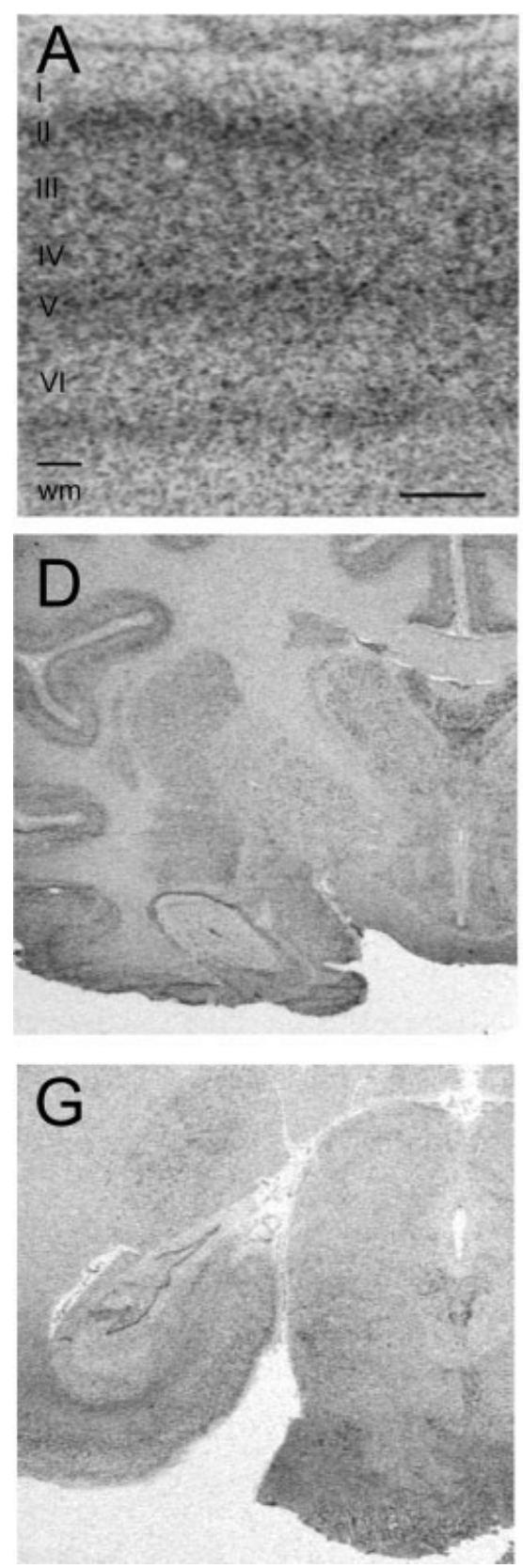
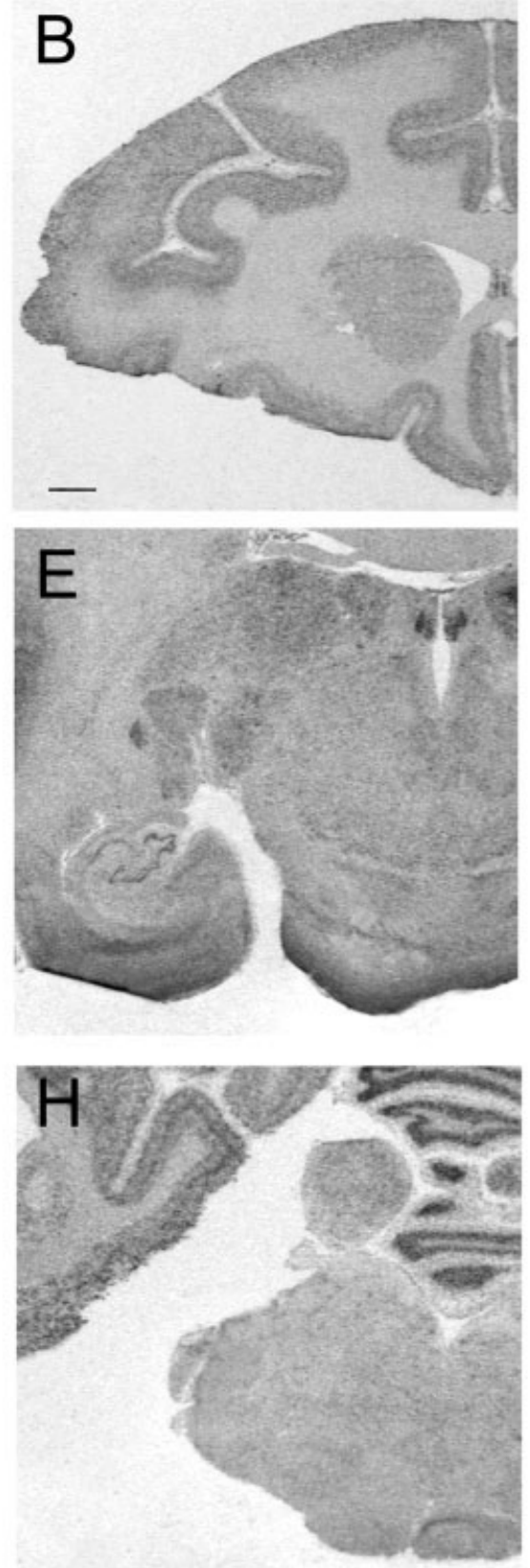
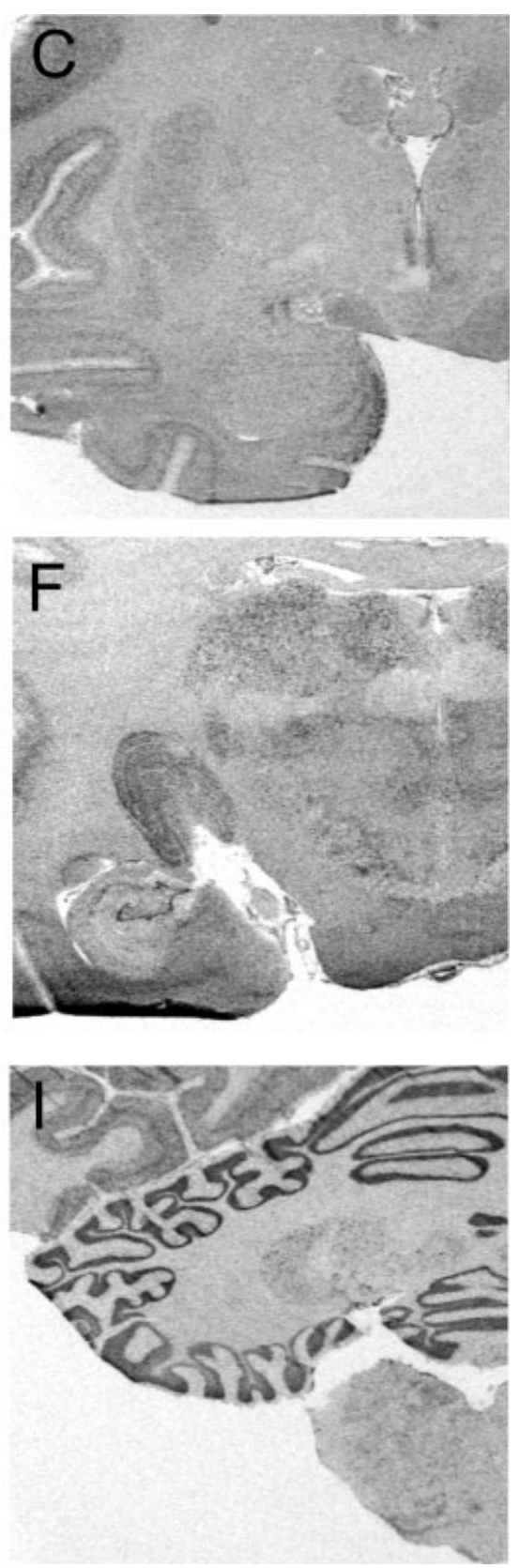

Fig. 10. KIAA1719 mRNA expression. A: In situ hybridization in the neocortex (primary visual area 17) showing distinct laminar distribution. Scale bar $=500 \mu \mathrm{m}$. B-L: In situ hybridization in coronal sections at different anteroposterior levels. Scale bar $=5 \mathrm{~mm}$.

moderate levels (Fig. 6B). GluR4 expression was almost imperceptible (Fig. 6E). The only PSD proteins expressed in the red nucleus were NSF (Fig. 6F) and syntenin (Fig. $6 \mathrm{I}$ ), both at high levels, especially in the parvocellular region.

Substantia nigra. GluR1 was highly expressed in both parts of the substantia nigra, but the highest expression was observed in the pars compacta (SNC) (Fig. 6B). GluR2 and GluR3 were expressed in the same pattern as that of GluR1, but at lower levels (Figs. 6C,D, 13A,B). GluR4 mRNA was not detected (Fig. 6E). All PSD proteins were expressed in both parts of SN. NSF, PICK1, and syntenin had the highest expression (Fig. 6F,G,I), stargazin moderate levels (Fig. $6 \mathrm{H}$ ), followed by KIAA1719 with the lowest abundance (Fig. 11F).

\section{Pons}

With the exception of the principal sensory nucleus of the trigeminal nerve (Pr5), which had high levels of GluR3 and GluR4 expression (Fig. 8D,E), and the lateral parabrachial nucleus (LPB), with high expression levels of GluR1 and GluR2 (Fig. 8B,C), the rest of the structures in 

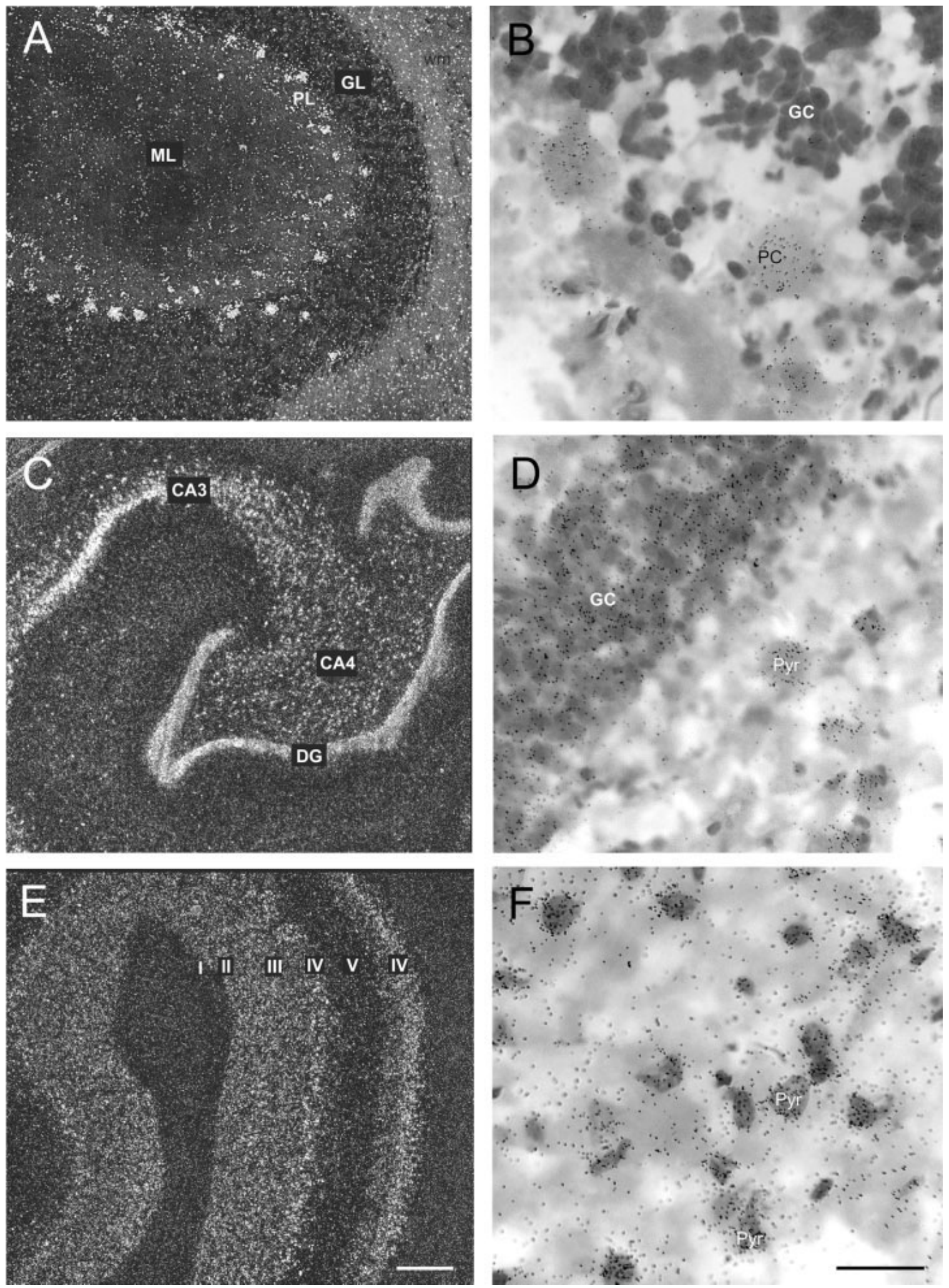

Fig. 11. Photomicrographs of emulsion-dipped slides. A,B: Cerebellar cortex (GluR3 mRNA expression in Purkinje cells). ML: molecular layer; PL: Purkinje layer; GL: granular layer; GC: granule cell; PC: Purkinje cell; Pyr: pyramidal cell. C,D: Hippocampus (stargazin

transcript expression in CA3, CA4, and dentate gyrus). E,F: Cerebral neocortex (laminar expression of NSF mRNA). A,C,E: 10× Darkfield microscopy. Scale bar $=5 \mathrm{~mm}$. B,D,F: $40 \times$ Nomarski microscopy. Scale bar $=500 \mu \mathrm{m}$ 
the pons showed very low to no expression of the AMPA subunits (Fig. 8B-E). In contrast, the PSD proteins delineated some pontine structures very sharply, with high levels of expression. NSF was the most prominently expressed in the pons, abundant in the central gray of the pons (CGP), the pontine raphe nucleus ( $R P n)$, and the pontine nuclei (Pn) (Fig. 7F). PICK1 was moderately expressed in the Pn (see below).

Pontine tegmentum. Pontine reticular formation. GluR3 was the AMPA subunit with the highest level of expression in the reticular formation of the pons, especially in the caudal pontine reticular nucleus (CPn) (Fig. 8D). NSF was highly expressed in all divisions of the pontine reticular formation, in contrast to the rest of the PSD proteins that were present at only low to moderate levels in these nuclei (Fig. 8F).

Superior olivary complex. All of the AMPA subunits and their associated PSD proteins were expressed in the superior olivary complex (SOC) (Fig. 8). All of the transcripts were highly expressed in the medial superior olivary nucleus (MSO). In the lateral olivary nuclei (LSO) only GluR3 and the PSD proteins were expressed (Fig. $8 \mathrm{~F}, \mathrm{G}, \mathrm{I})$. NSF had high expression in this nucleus, while the other PSD proteins were expressed at moderate levels. GluR2 was the only AMPA subunit absent in the trapezoid nuclei $(\mathrm{Tz})$, where the rest had moderate to low expression. In Tz, NSF was highly expressed, while the other PSD proteins had moderate to low expression levels (Fig. $8 \mathrm{~F}-\mathrm{I})$. None of the transcripts were seen in the trapezoid body (tz) (Fig. 8).

Basal pons. Pontine nuclei. These nuclei have a high degree of mismatch between the level of expression of AMPA subunits and associated PSD proteins (Figs. 6, 7). GluR1 and GluR3 had moderate levels of expression (Fig. 7B,D), while GluR2 and GluR4 were almost imperceptibly expressed (Fig. 7C,E). In contrast, all of the PSD proteins had moderate (stargazin, KIAA1719) to very high (NSF, PICK1, and syntenin) expression in the pontine nuclei (Figs. 6F-I, 7F-I, 10G).

\section{Medulla oblongata}

Vestibular nuclei. All of the AMPA receptor subunits were expressed in the vestibular nuclei. GluR1, GluR2, and GluR4 were all expressed at moderate levels and GluR3 at low levels (Fig. 9B-E). The PSD protein with the highest expression in the vestibular nuclei was syntenin (Fig. 9I), followed by NSF at moderate density (Fig. 9F), and PICK1 and stargazin with densities similar to those of GluR1 and GluR2 (Fig. 9G,H).

Cochlear nuclei. Moderate expression was seen in the cochlear nuclei, especially in the dorsal nucleus (DCN), for all four AMPA subunits, and in the ventral nuclei (VCN) for GluR3 and GluR4 (Figs. 8B-E, 9B-E). NSF, PICK1, and syntenin were highly expressed in DCN and VCN (Figs. 8F,G,I, 9F,G,I), while stargazin (Figs. 8I, 9I) and KIAA1719 (not shown) had moderate expression.

Raphe nuclei. GluR3 and GluR4 expression in the medullary raphe nucleus were both high compared to the low density of GluR1 and GluR2 (Fig. 9B-E). The least expressed PSD proteins in this nuclear complex were PICK1 and stargazin (Fig. 9G,H). On the other hand, NSF and syntenin were both highly expressed in the raphe nuclei (Fig. 9F,I).

Inferior olivary nuclear complex. In the inferior olive, GluR1 and GluR2 were highly expressed (Fig. 9B,C), followed by GluR4 at moderate levels (Fig. 9E). In contrast, GluR3 expression was practically absent in this nucleus (Fig. 9D). Stargazin had low expression, similar to that of GluR3 (Fig. 9H). The other PSD proteins, including KIAA1719, had very high expression levels in this structure (Fig. 9F,G,I, 10I).

\section{Cerebellum}

Deep cerebellar nuclei. GluR1 and GluR2 had moderate expression in the dentate and the emboliform nuclei, with lower expression in the globose and fastigial nuclei (Fig. 9B,C). GluR3 was expressed in all of the cerebellar nuclei, with the highest density in the dentate nucleus (Fig. 9D). GluR4 was the least expressed AMPA subunit (Fig. 9E).

Contrasting with the low to moderate expression levels of the AMPA receptor subunits, the PSD proteins were more highly expressed in all of the cerebellar nuclei. Stargazin and KIAA1719 were moderately expressed, although both were still higher than expression levels of the AMPA subunits (Figs. 9H, 10I). The PSD proteins were highly expressed in the dentate nucleus; NSF and syntenin were also highly expressed in the emboliform, globose, and fastigial nuclei. PICK1 and stargazin were both expressed in these nuclei but at lower levels (Fig. 9F,G,I).

Cerebellar cortex. All of the AMPA subunits and PSD proteins were expressed in the cerebellar cortex. Interestingly, the expression of GluR3 in the cortex was different than that of the other AMPA subunits, as it was expressed exclusively by the Purkinje cells (Figs. 9D, 12A,B), while GluR1, GluR2, and GluR4 showed expression in both the granule and Purkinje cell layers (Fig. 9B,C,E). All of the PSD proteins studied were expressed in all layers of the cerebellar cortex, including low expression in the molecular layer (Figs. 9F-I, 10I).

\section{DISCUSSION}

In this study, we describe the anatomical distribution of the transcripts encoding the AMPA receptor subunits (GluR1-GluR4), four of the PSD intracellular proteins related to them (NSF, PICK1, stargazin, and syntenin), and a fifth PDZ protein (KIAA1719) not yet characterized in macaque or human with a high homology to the rat protein ABP. The distribution of the transcripts encoding all these proteins was visualized with in situ hybridization histochemistry. Although some studies on AMPA receptor distribution have been previously reported in both rat and monkey brain (Petralia and Wenthold, 1992; Huntley et al., 1994; Garyfallou et al., 1996; Kohama and Urbanski, 1997; Jones et al., 1998; Munoz et al., 1999; Xu et al., 2003), the present study represents the first comprehensive and detailed comparison in the primate brain of the distribution of all four AMPA subunit transcripts. While the PSD proteins studied have all been characterized and their molecular properties described in vitro, this is the first report on their regional distribution in the macaque brain. This is also the first report on the expression of the transcript encoding the protein KIAA1719.

\section{Functional implications of the anatomical distribution of the AMPA receptor subunits and their related PSD proteins}

In AMPA receptors, properties of the ion channel are controlled in a cell-specific manner through differential 

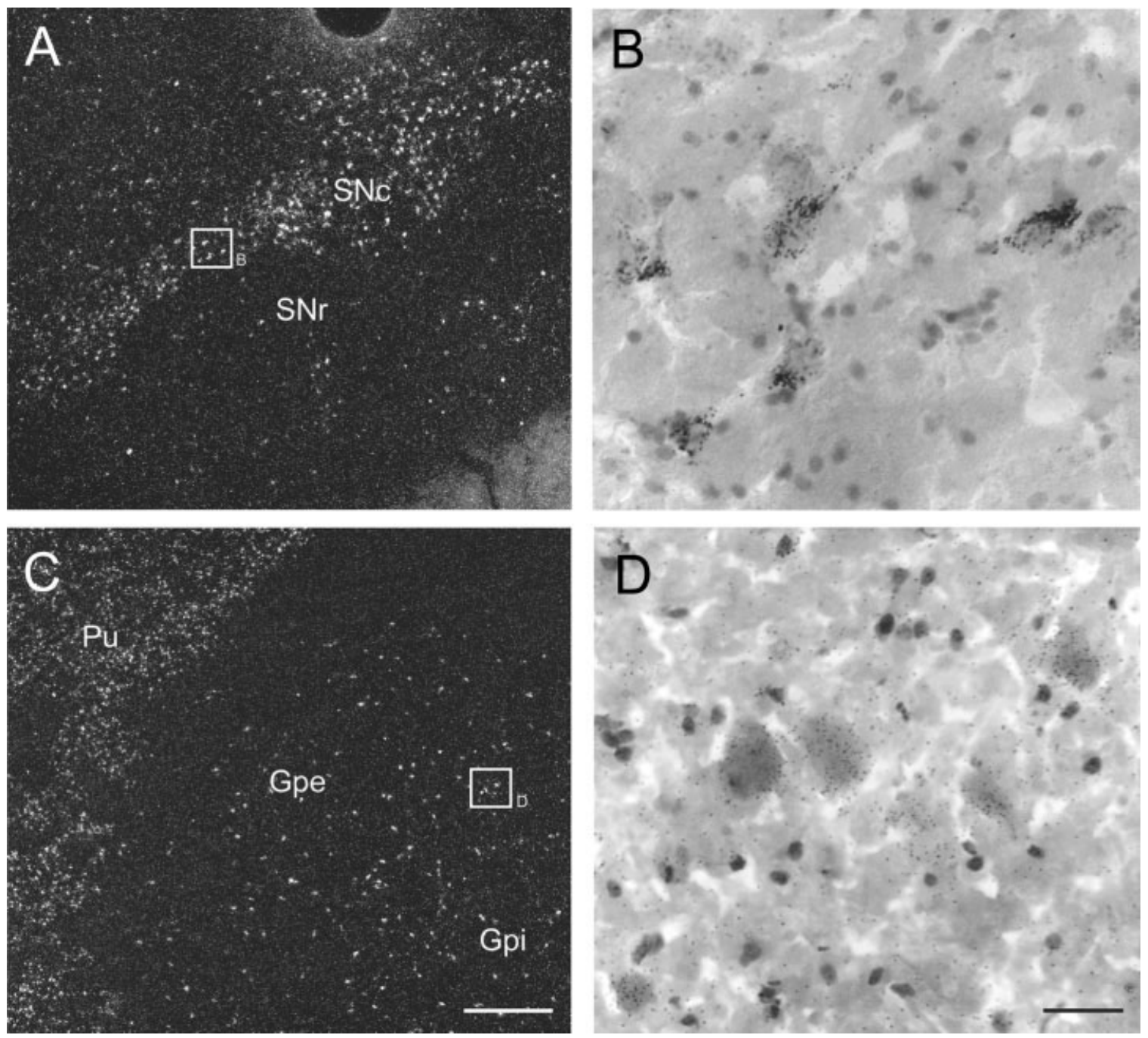

Fig. 12. Photomicrographs of emulsion-dipped slides. A: Substantia nigra (GluR2 mRNA expression in both pars compacta (SNc) and pars reticulata (SNr)). B: GluR2 mRNA expression in cells of the SNc. C: Globus pallidus (syntenin transcript expression in the external

subunit expression and RNA editing. Thus, the kinetics of the AMPA receptor, pharmacological sensitivity, and synaptic transmission are determined by the subunits that form the AMPA receptors in a specific synapse (Hollmann and Heinemann, 1994). Our results reveal an extensive, but specific, distribution of the transcripts encoding the AMPA receptor subunits in the primate brain, and demonstrate both similarities and differences in gene expression of AMPA receptors subunits. Key structures like the thalamus and the cerebellum are among the structures where the clearest differences in the distribution of AMPA subunits were observed, consistent with previous reports on mRNA expression (Gallo et al., 1992; Petralia and Wenthold, 1992; Jones et al., 1998).

The stoichiometry of the AMPA receptors in different brain structures determines not only their kinetics and ion permeability, but also the synaptic function of the postsynaptic cells in which they are located. In the case of segment of the globus pallidus (GPe). (Pu: putamen). D: syntenin mRNA expression of cells in the GPe. A,C: $10 \times$ Darkfield microscopy. Scale bar $=5 \mathrm{~mm}$. B,D: $40 \times$ Nomarski microscopy. Scale bar $=500$ $\mu \mathrm{m}$.
AMPA receptors, the presence, absence, or the relative density of one subunit will predict what processes for receptors trafficking and delivery to synapses will be present, and how the postsynaptic cells in a given brain structure will respond to synaptic activity. GluR1containing receptors are delivered into synapses by longterm potentiation (LTP) or calcium/calmodulin-dependent protein kinase II (CaMKII) activity driven by NMDA receptor activation (Shi et al., 1999, 2001; Hayashi et al., 2000; Shi, 2001). On the other hand, GluR4-containing AMPA receptors are driven into synapses by spontaneous activity during early development independent of CaMKII activity (Zhu et al., 2000).

In the last decade a model has been developed to explain how the subunit composition of the AMPA receptors controls two distinct processes of synaptic receptor delivery (Fig. 13). The first process consists of a continuous and rapid activity-independent recycling from nonsynaptic to 


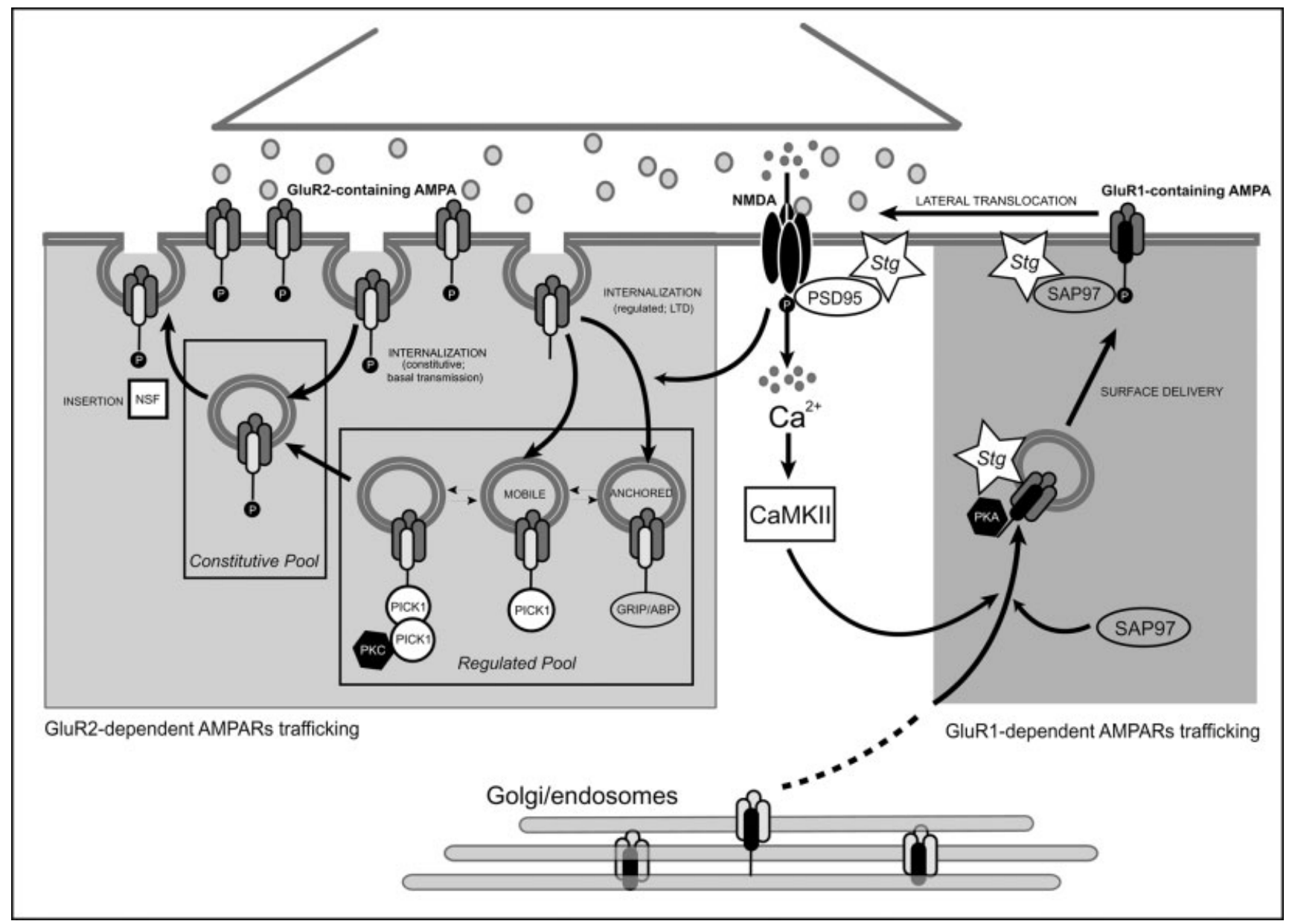

Fig. 13. Subunit composition of the AMPA receptor controls two distinct processes of synaptic receptor delivery. The first process consists of a continuous and rapid activity-independent recycling from nonsynaptic to synaptic sites in the cell. This process requires interactions between the GluR2 subunit and the intracellular protein N-ethylmaleimide-sensitive factor (NSF), suggesting that only GluR2containing receptors contribute to maintaining the "constitutive pool" of synaptic AMPA receptors. A second process of synaptic AMPA receptor trafficking and synaptic targeting has been described as activity-dependent, triggered by NMDA receptor activation, and modulates the "regulated pool" of AMPA receptors. That process is driven by PDZ interactions between C-terminal regions of the AMPA subunits and some intracellular proteins of the postsynaptic density (PSD), allowing them to interact with a variety of PSD proteins. synaptic sites in the cell (Nishimune et al., 1998; Osten et al., 1998; Song et al., 1998; Luscher et al., 1999; Luthi et al., 1999; Noel et al., 1999). This process seems to require interactions between the GluR2 subunit and the intracellular protein NSF, suggesting that only GluR2-containing receptors contribute to maintaining the "constitutive pool" of synaptic AMPA receptors. A second process of synaptic AMPA receptor trafficking and synaptic targeting has been described as activity-dependent, triggered by NMDA receptor activation and controlled by PDZ proteins like PICK1 and syntenin that modulate the "regulated pool" of AMPA receptors.

Postsynaptic neurons with receptors preferentially containing the GluR2 subunit preserve stable transmission for long periods of time even in the absence of neuronal activity. This is due to the first receptor trafficking process described, the interaction of this subunit with NSF, producing the fast recycling of the constitutive pool of AMPA receptors and the insertion of receptors back into the postsynaptic membrane from the activity-regulated pool of AMPA receptors internalized in vesicles by their binding to proteins like ABP, GRIP, PICK-1. Our results suggest that this is a key process in the cerebral cortex, the hippocampus, the corticomedial and the central amygdaloid nucleus, claustrum, subthalamic nucleus, the inferior colliculus, the pars compacta (but not the pars reticulata) of the substantia nigra, the pontine reticular formation, the superior olivary cortex, and the cerebellar cortex (but not the cerebellar deep nuclei). On the other hand, those regions rich in GluR1 subunits represent the structures in which plasticity is essential for their function, and are those with a slower trafficking process consisting of the insertion of newly synthesized AMPA receptors from the Golgi apparatus, in response to increased synaptic transmission, via their binding to proteins like SAP97. Structures in which this process seems most active are the frontal lobe, insula, and cingulate gyrus of the neocortex, the hippocampal formation, striatum, the basolateral and corticomedial nuclear groups of the amygdala, claustrum, septum, thalamus, hypothalamus, the pars reticulata of 
the substantia nigra, the inferior olive, and the cerebellum.

\section{PDZ proteins: PICK1 and syntenin}

In our results, we observed several structures in which the distribution of PICK1 matched that of GluR2-GluR4. For instance, overlapping expression patterns were observed in the striatum, the corticomedial and central amygdaloid nuclei, the reticular nucleus, and the anterior nuclear group of the thalamus (especially with GluR3, but not with GluR2), in the subthalamic nucleus, inferior and superior colliculi, substantia nigra, superior olivary complex, and the cerebellar cortex.

PICK1 contains a single PDZ domain that not only interacts with GluR2-GluR4, but also binds to PKCa, ephrin ligands and receptors, ADP ribosylation factor, the dopamine transporter, mGluR3, and mGluR7a, as well as atypical PDZ binding motifs (TIS21) (Staudinger et al., 1997; Dev et al., 1999, 2001; Xia et al., 1999; Lin et al., 2001; Torres et al., 2001). The wide spectrum of binding targets characterized by in vitro studies likely explains many of the mismatches between AMPA receptor subunits and PICK1 in many brain regions in our study. For instance, in the neocortex the laminar distribution of PICK1 did not match the expression patterns of GluR2GluR4, the AMPA subunits with which it has been reported to interact. Surprisingly, it coincided best with GluR1 expression in cortical layers V and VI; yet in most in vitro studies it does not prefer GluR1. Another example of mismatch between PICK1 and GluR2-4 is in the ventral, intermediate, and anterior nuclei of the thalamus, where PICK1 was highly expressed, but only GluR1 was significantly expressed. These mismatches may be explained by a recently published study on PICK1 binding targets (Hirbec et al., 2002), in which interaction between PICK1 and GluR1, not previously reported, was found. It is unclear, however, what the functional role of the interaction of PICK1 and GluR1 might be; one possibility is that it might become relevant in the absence of other competitive GluR1-interacting proteins and is only important at certain developmental stages, cell states, or cell types (Hirbec et al., 2002). Assuming that an interaction between GluR1 and PICK1 does occur in vivo, our results suggest that two of these specific cell types in which it can be present are the thalamocortical relay neurons of the thalamus and the cells of the output layers of the cerebral cortex, in layers V and VI.

In the ascending auditory pathways, our results are consistent with the immunolocalization of PICK1 in the adult rat (McInvale et al., 2002). In the rat, PICK1 is observed in many nuclei of the central auditory system, including the dorsal cochlear nucleus, anteroventral cochlear nucleus, posteroventral cochlear nucleus, some divisions of the superior olivary complex, inferior colliculus, medial geniculate body, and primary auditory cortex (McInvale et al., 2002). Our data indicate that the role of PICK1 in both basic synaptic function and plasticity in the auditory system is probably unique to this pathway in which, as we show here, the expression of the protein is very extensive.

The matches between PICK1 and GluR2/3 are crucial for the localization of some forms of regulation of the glutamatergic synapses by removal, trafficking, and targeting of AMPA receptors. It has been shown that the PICK1-GluR2 interaction is required for the expression of some forms of LTD (Xia et al., 2000; Kim et al., 2001), suggesting that PICK1 stimulates AMPA receptor removal from the postsynaptic membrane by endocytosis. Other studies have hypothesized a model by which AMPA receptors are secured in intracellular pools via association of the GluR2 subunit with GRIP and/or ABP. These "gripped" receptors are immobile and only GRIP exchange by PICK1 makes them mobile and ready to be inserted back in the membrane. This occurs due to the phosphorylation of ser880 of GluR2 by PKCa, targeted by PICK1, resulting in a state that prevents the rebinding of GRIP. Ser880-phosphorylated AMPA receptors are mobile and available for surface expression (Chung et al., 2000; Daw et al., 2000; Kim et al., 2001; Perez et al., 2001; Hirbec et al., 2003).

Syntenin was first identified to interact with the cytoplasmic C-terminal of syndecans (Grootjans et al., 1997). It contains two nearly adjacent PDZ domains that can recognize multiple $\mathrm{PDZ}$ binding motifs, including those found in neurofascin, proTGF $\alpha$, syndecans, ephrin-B2, EphA7, and r-PTP tifs such as in Schwabbomin-FEEL (Kohler et al., 1994; Boudin et al., 2000; Dev et al., 2000, 2001). Syntenin also interacts with all four AMPA receptor subunits, which likely explains its completely overlapping distribution with the AMPA subunits in this study.

\section{Interactions with and regional distribution of NSF with potential binding partners for AMPA receptor recycling}

Biochemical studies have demonstrated that NSF is a homohexameric ATPase (Hanson et al., 1997; Fleming et al., 1998) whose hydrolytic activity is essential in membrane fusion events (Rothman, 1994; Whiteheart et al., 1994). Presynaptically, NSF acts in the disassembly of the SNARE complex in a reaction mediated by ATP hydrolysis (Sollner et al., 1993; Hayashi et al., 1995). NSF has also been identified among the proteins of the postsynaptic density of glutamatergic synapses. Biochemical fractionation studies have reported that NSF interacts with the C-terminus of the GluR2 subunit in vitro, and it has been suggested that it regulates AMPA receptor function (Song et al., 1998). Nishimune et al. (1998) examined the AMPA receptor subunits to which NSF binds, finding that it interacts very strongly with GluR2, weakly with GluR3, and not at all with GluR1 or GluR4. They suggested that this specificity might be related to the function of the glutamate receptor-NSF interaction. The inclusion of the GluR2 subunit, in its edited form, in the AMPA receptor complex renders the channel impermeable to $\mathrm{Ca}^{2+}$. Since more than $99 \%$ of GluR2 subunits are edited, essentially all GluR2-containing AMPA receptors are $\mathrm{Ca}^{2+}$ impermeable. Therefore, AMPA receptors inserted into the plasma membrane via an NSF-dependent mechanism will have a low $\mathrm{Ca}^{2+}$ permeability (Nishimune et al., 1998).

A model of interactions between NSF and GluR2containing AMPA receptors (Fig. 13) suggests a rapid NSF-dependent insertion of a fraction of preassembled GluR2-containing AMPA receptors into the postsynaptic membrane. This has been proposed as a mechanism for recycling functional AMPA receptors under basal conditions, which can modulate both basal synaptic transmission and synaptic plasticity (Nishimune et al., 1998). 
In our results, NSF distribution matched the distribution of GluR2 and GluR3 in numerous structures. In the forebrain, clear matches were found in the cerebral cortex, the hippocampal formation, the striatum, some nuclei of the amygdala, and the claustrum. In the midbrain, both subunits and NSF were expressed in the colliculi, sagulum, dorsal raphe, and the pars compacta of the substantia nigra. In the hindbrain, although we found several differences in the expression of these two molecules in many structures, the distribution and density of expression of NSF mRNA coincides with that of both the GluR2 and GluR3 subunits in the pontine reticular formation and the superior olivary complex. Finally, in the medulla and the cerebellar cortex there was an almost complete overlap between NSF and GluR2 and GluR3.

Even though we found numerous similarities between the distribution of NSF and the AMPA subunits to which it binds, there were also mismatches in some regions of the brain. The most noticeable mismatches were found in the thalamus, where NSF is highly expressed but not GluR2. Differences were also found in some of the nuclei of the hypothalamus, like the posterior and the dorsal areas, in the red nucleus of the midbrain tegmentum, the pontine raphe nucleus, and especially in the cerebellar nuclei. The presynaptic role of NSF can easily explain these mismatches in some structures where GluR2 or GluR3 were not expressed but very high expression of NSF transcript was observed.

Another possible reason for such differences in regional expression may be due to the fact that the fast recycling of AMPA receptors under basal conditions may not be critical in glutamatergic synapses of structures like the thalamus or the cerebellar nuclei, more enriched in GluR1containing AMPA receptors, as compared to the hippocampus, where almost all the studies describing this model have been conducted. It is known that LTP and LTD involve an increase and decrease in postsynaptic AMPA receptor function (Davies et al., 1989) and it is believed that these processes may be mediated by the rapid insertion of AMPA receptors into synapses (Isaac et al., 1995; Benke et al., 1998; Liao et al., 2001), and probably regulated by NSF-GluR2 interactions (Nishimune et al., 1998). Thus, our results on the mismatched localization of NSF and GluR2 in the thalamus and the pontine nuclei, but their colocalization in the hippocampus and amygdala, are consistent with that hypothesis.

\section{Localization of stargazin: regional expression and synaptic targeting of AMPA receptors}

Stargazin was the first transmembrane protein found to interact with AMPA receptors. It has four transmembrane domains (Letts et al., 1998) and its cytosolic C-terminal tail contains a PDZ-binding site, which binds to PDZ domains in PSD-95 and related proteins (Chen et al., 2000a). In the rodent, stargazin is enriched in the cerebellum and hippocampus. In the stargazer mouse mutant, AMPA receptors fail to traffic to the plasma membrane or to the synapse in cerebellar granule cells, and overexpression of a dominant negative stargazin construct reduces synaptic AMPA receptor function in hippocampal neurons (Chen et al., 2000). These observations suggest that stargazin-like mechanisms might also regulate AMPA receptors in the forebrain. Our data reveal that there is extensive expres- sion of this gene in the forebrain, including the neocortex, striatum, amygdala, thalamus, and hypothalamus.

It has been suggested that stargazin interacts with PDZ-domains of proteins from the PSD95 family. Supporting this, we have observed that the expression of stargazin extensively overlaps with that of PSD-95 mRNA in the primate brain (S.M. Clinton, pers. commun.). Among the PDZ proteins we studied, stargazin had a unique pattern of expression. It had a very low density in structures such as the basal ganglia and the inferior colliculus, where both PICK1 and syntenin were highly expressed. The most intriguing distribution was observed in the hippocampus. Stargazin is highly expressed in the dentate gyrus and CA2-CA4, but is practically absent from the pyramidal cells of CA1.

CA1 pyramidal cells receive glutamatergic input from the entorhinal cortex through the perforant path and from CA3 through Schaffer collaterals, and these inputs are mediated primarily by AMPA and NMDA receptors. In the hippocampus, calcium currents mediated by voltageactivated calcium channels are known to be involved in kindling. The relevance of calcium currents in epilepsy is further underscored by the fact that mutations in voltagedependent calcium channels in mice are often associated with epilepsy (Letts et al., 1998). Stargazin has been classified as a member of the $\gamma$-like subunit family of the skeletal muscle calcium channel. Coexpression studies revealed a modulatory function of the $\gamma$-subunit on the L-type calcium channel; these include changes in peak current and in the activation and inactivation kinetics (Singer et al., 1991; Wei et al., 1991; Eberst et al., 1997). In chronically epileptic rats, the sustained high-voltageactivated (HVA) calcium current characteristics show opposite changes in CA1 vs. the dentate gyrus of the hippocampus. HVA calcium entry for a standard depolarization in CA1 neurons is decreased relative to control neurons, while in the dentate gyrus HVA calcium entry is increased (Gorter et al., 2002a). It has been suggested that the specific effects of these changes have consequences for neuronal firing patterns and functioning. Synaptic changes contribute to the increased excitability in CA1 and dentate gyrus in epilepsy (Lothman et al., 1995; Mangan et al., 1995; Rempe et al., 1995; Gorter et al., 2002b). It has been hypothesized that the differences in response of CA1 and the dentate gyrus in status epilepticus might be attributed to the loss of the calcium binding protein, Calbindin- $\mathrm{D}_{28 \mathrm{~K}}$ (Nagerl et al., 2000). However, our results suggest another possibility: we observed extremely low expression of stargazin mRNA in CA1. In the absence of stargazin in CA1, compared to the dentate gyrus granule cells, differences observed in calcium entry levels and electrophysiological responses might be due to the lack of the "modulatory" $\gamma$-like subunit family, to which stargazin belongs, of the skeletal muscle calcium channel.

Stargazin has also been described to act in the trafficking of AMPA receptors by two different mechanisms. First, stargazin regulates delivery of AMPA receptors to the membrane surface and this function does not require the PDZ-binding domain. Second, stargazin mediates synaptic targeting of AMPA receptors from extrasynaptic sites and this function does require the PDZ-binding C-terminus. The scarcity of stargazin in CA1 may explain earlier observations of the existence of pathway-specific properties of AMPA and NMDA-mediated transmission in CA1 hippocampal pyramidal cells, in which a spatial dif- 
ference in the NMDA/AMPA charge ratio between the perforant path input and the Schaffer collaterals was described (Otmakhova et al., 2002). They observed that the perforant path synapses are distributed in the stratum lacunosum moleculare $\sim 300 \mu \mathrm{m}$ from the cell body, whereas the Schaffer collaterals make synapses in the stratum radiatum in a more proximal location. Stargazin has been specifically associated with lateral movements of AMPA receptors from the cell body to the dendritic spines by interaction with PDZ proteins like PSD-95 that bind to NMDA receptors. The low expression of stargazin in CA1, then, might allow the higher NMDA/AMPA ratio in the distal perforant path synapses from the entorhinal cortex afferents previously reported (Otmakhova et al., 2002).

\section{Putative AMPA-related PDZ protein: KIAA1719}

In our attempt to map the expression of PDZ proteins in the primate brain, we were interested in visualizing the mRNA encoding the protein ABP (AMPA receptor-binding protein). We found that the $\mathrm{ABP}$ sequence was not yet characterized in human. Interestingly, using the rat $\mathrm{ABP}$ sequence, we found a high homology sequence in the human genome in one of the KIAA cDNA entries of the Kazusa cDNA project, encoding a protein named KIAA1719. The Kazusa cDNA sequencing project has focused on identifying and characterizing the unidentified gene products of long cDNA clones which direct the synthesis of large proteins $(>50 \mathrm{kDa})$ (Ohara et al., 1997). More than 2,000 human cDNA sequences have been published to date (Nagase et al., 1997). The results of the sequence analysis, expression profiling, and chromosomal mapping for respective cDNAs have been summarized in the HUGE database, systematically designating the cDNA entries as KIAA plus a four-digit number.

In our case, we included in this study the expression of the human clone identified as KIAA1719 (Acc. No. $\mathrm{AB} 051506)$ that has a length of 7,706 bp. The predicted encoded protein is 1,050 amino acids in length. The result of a homology search showed a maximum homology of $89.2 \%$ with the rat $\mathrm{ABP}$ sequence, and a homology of $87.7 \%$ with rat GRIP-1, as expected because of the existence of a splice variant ABP-L, also named GRIP-2 (Srivastava et al., 1998). In addition, we investigated if the N-terminal of KIAA1719, where the PDZ domains are located, coincided with the N-terminus of ABP in rat. We found a complete match between the two sequences, and a mismatch of only 10 amino acids with the N-terminal end of rat GRIP1. The results of a motif/domain search confirmed these observations, as it found seven PDZ domains in KIAA1719, identical to those found in rat ABP.

The expression of KIAA1719 was lower compared to the other PDZ proteins in this study, but it had some similarities in its distribution in the cerebellum and the forebrain. It was particularly enriched in the cerebellum and the hippocampus, but restricted to CA3 and the dentate gyrus. It was also present in the neocortex, basal ganglia, and some thalamic nuclei, with especially high levels of expression in DLG and habenular nuclei. To date, the only data available on the location of $\mathrm{ABP}$ in rat has shown that it is present in the neocortex and in the hippocampus (Burette et al., 2001; DeSouza et al., 2002). It has been suggested that ABP binds the C-termini of the GluR2 and GluR3 AMPA receptor subunits via PDZ domains (Srivastava et al., 1998). Our results, however, found little overlap between KIAA1719 and the distribution of GluR2 and GluR3. If KIAA1719 is the human homolog of rat ABP, then the interactions observed in vitro with GluR2 and GluR3 might be restricted to the forebrain and the cerebellum in very specific areas where they are coexpressed. For example, in the case of the hippocampus, it would be only in the dentate gyrus and CA3.

The other possibility is that KIAA1719 is a novel PDZ protein, with high homology to $\mathrm{ABP}$ in rat, as ABP has with GRIP-1 (Srivastava et al., 1998), but with a different functional profile and different targets for its PDZ interactions. Further studies with coimmunoprecipitation and coimmunostaining must be done in order to assess this possibility.

\section{SUMMARY}

We have identified the regional and cellular distribution of four AMPA-related PSD proteins and a fifth putative PDZ protein with a high homology with $\mathrm{ABP}$, still not characterized in human. Although the coexpression seen in some brain structures of these proteins and the AMPA subunits provide another confirmation of their close interactions, the mismatches seen in this study suggest that they have more functions than the ones that have been described by in vitro studies. Future studies will elucidate other roles of these proteins in the postsynaptic machinery. It should be noted that all of this work was done in female macaques, and generalization to the male should be done with some caution. In addition, we do not have information on the hormonal status of these animals, and it is possible that phase of the estrous cycle may have some impact on the expression of some of these genes.

There are numerous unanswered questions regarding the function of the PSD proteins and the consequences of their binding to AMPA receptors in synaptic transmission. Recent studies have implicated some PSD proteins, including NSF, PSD95 or SAP97, with neuropsychiatric disorders, suggesting that dysfunctions in AMPA receptor trafficking or anchoring to the synaptic membrane or signal transduction may be disrupted in some mental illnesses like schizophrenia (Mirnics et al., 2000, 2001; Ohnuma et al., 2000; Imai et al., 2001; Mirnics and Lewis, 2001). Although we are at an early stage in terms of our knowledge of the molecular mechanisms of these proteins in synaptic transmission, future work on their function and regulation may provide further understanding of the role of these molecules in normal synaptic function as well as disorders of the brain.

\section{LITERATURE CITED}

Bear M, Abraham W. 1996. Long-term depression in the hippocampus. Annu Rev Neurosci 19:437-462.

Benke TA, Luthi A, Isaac JT, Collingridge GL. 1998. Modulation of AMPA receptor unitary conductance by synaptic activity. Nature 393:793797.

Bliss TV, Collingridge GL. 1993. A synaptic model of memory: long-term potentiation in the hippocampus. Nature 361:31-39.

Boudin H, Doan A, Xia J, Shigemoto R, Huganir RL, Worley P, Craig AM. 2000. Presynaptic clustering of mGluR7a requires the PICK1 PDZ domain binding site. Neuron 28:485-497.

Braithwaite SP, Meyer G, Henley JM. 2000. Interactions between AMPA receptors and intracellular proteins. Neuropharmacology 39:919-930.

Braithwaite SP, Xia H, Malenka RC. 2002. Differential roles for NSF and GRIP/ABP in AMPA receptor cycling. Proc Natl Acad Sci USA 99: 7096-7101.

Brose N, Huntley GW, Stern-Bach Y, Sharma G, Morrison JH, Heinemann SF. 1994. Differential assembly of coexpressed glutamate receptor subunits in neurons of rat cerebral cortex. J Biol Chem 269:16780-16784.

Burette A, Wyszynski M, Valtschanoff JG, Sheng M, Weinberg RJ. 1999. Characterization of glutamate receptor interacting protein- 
immunopositive neurons in cerebellum and cerebral cortex of the albino rat. J Comp Neurol 411:601-612.

Burette A, Khatri L, Wyszynski M, Sheng M, Ziff EB, Weinberg RJ. 2001. Differential cellular and subcellular localization of ampa receptorbinding protein and glutamate receptor-interacting protein. J Neurosci 21:495-503.

Chen L, Chetkovich DM, Petralia RS, Sweeney NT, Kawasaki Y, Wenthold RJ, Bredt DS, Nicoll RA. 2000. Stargazin regulates synaptic targeting of AMPA receptors by two distinct mechanisms. Nature 408:936-943.

Cho KO, Hunt CA, Kennedy MB. 1992. The rat brain postsynaptic density fraction contains a homolog of the Drosophila discs-large tumor suppressor protein. Neuron 9:929-942.

Chung HJ, Xia J, Scannevin RH, Zhang X, Huganir RL. 2000. Phosphorylation of the AMPA receptor subunit GluR2 differentially regulates its interaction with PDZ domain-containing proteins. J Neurosci 20:72587267.

Davies SN, Lester RA, Reymann KG, Collingridge GL. 1989. Temporally distinct pre- and post-synaptic mechanisms maintain long-term potentiation. Nature 338:500-503.

Daw MI, Chittajallu R, Bortolotto ZA, Dev KK, Duprat F, Henley JM, Collingridge GL, Isaac JT. 2000. PDZ proteins interacting with C-terminal GluR2/3 are involved in a PKC-dependent regulation of AMPA receptors at hippocampal synapses. Neuron 28:873-886.

D'Eustachio P. 1994. Mouse chromosome 12. Mamm Genome 5 Spec No: S181-195.

DeSouza S, Fu J, States BA, Ziff EB. 2002. Differential palmitoylation directs the AMPA receptor-binding protein ABP to spines or to intracellular clusters. J Neurosci 22:3493-3503.

Dev KK, Nishimune A, Henley JM, Nakanishi S. 1999. The protein kinase $\mathrm{C}$ alpha binding protein PICK1 interacts with short but not long form alternative splice variants of AMPA receptor subunits. Neuropharmacology 38:635-644.

Dev KK, Nakajima Y, Kitano J, Braithwaite SP, Henley JM, Nakanishi S. 2000. PICK1 interacts with and regulates PKC phosphorylation of mGLUR7. J Neurosci 20:7252-7257.

Dev KK, Nakanishi S, Henley JM. 2001. Regulation of mglu7 receptors by proteins that interact with the intracellular C-terminus. Trends Pharmacol Sci 22:355-361.

Dong H, O'Brien RJ, Fung ET, Lanahan AA, Worley PF, Huganir RL. 1997. GRIP: a synaptic PDZ domain-containing protein that interacts with AMPA receptors. Nature 386:279-284.

Dong H, Zhang P, Song I, Petralia RS, Liao D, Huganir RL. 1999. Characterization of the glutamate receptor-interacting proteins GRIP1 and GRIP2. J Neurosci 19:6930-6941.

Eberst R, Dai S, Klugbauer N, Hofmann F. 1997. Identification and functional characterization of a calcium channel gamma subunit. Pflugers Arch 433:633-637.

Ehlers M, Zhang S, Bernhadt J, Huganir R. 1996. Inactivation of NMDA receptors by direct interaction of calmodulin with the NR1 subunit. Cell 84:745-755.

Fleming KG, Hohl TM, Yu RC, Muller SA, Wolpensinger B, Engel A, Engelhardt H, Brunger AT, Sollner TH, Hanson PI. 1998. A revised model for the oligomeric state of the N-ethylmaleimide-sensitive fusion protein, NSF. J Biol Chem 273:15675-15681.

Gallo V, Upson LM, Hayes WP, Vyklicky L Jr, Winters CA, Buonanno A. 1992. Molecular cloning and development analysis of a new glutamate receptor subunit isoform in cerebellum. J Neurosci 12:1010-1023.

Garyfallou VT, Kohama SG, Urbanski HF. 1996. Distribution of NMDA and AMPA receptors in the cerebellar cortex of rhesus macaques. Brain Res 716:22-28.

Gonzalez-Albo MC, DeFelipe J. 2000. Colocalization of glutamate ionotropic receptor subunits in the human temporal neocortex. Cereb Cortex 10:621-631.

Gorter JA, Borgdorff AJ, van Vliet EA, Lopes da Silva FH, Wadman WJ. 2002a. Differential and long-lasting alterations of high-voltage activated calcium currents in CA1 and dentate granule neurons after status epilepticus. Eur J Neurosci 16:701-712.

Gorter JA, van Vliet EA, Aronica E, Lopes da Silva FH. 2002b. Longlasting increased excitability differs in dentate gyrus vs. CA1 in freely moving chronic epileptic rats after electrically induced status epilepticus. Hippocampus 12:311-324

Grootjans JJ, Zimmermann P, Reekmans G, Smets A, Degeest G, Durr J, David G. 1997. Syntenin, a PDZ protein that binds syndecan cytoplasmic domains. Proc Natl Acad Sci USA 94:13683-13688.

Hanson PI, Roth R, Morisaki H, Jahn R, Heuser JE. 1997. Structure and conformational changes in NSF and its membrane receptor complexes visualized by quick-freeze/deep-etch electron microscopy. Cell 90:523-535.

Hayashi T, Yamasaki S, Nauenburg S, Binz T, Niemann H. 1995. Disassembly of the reconstituted synaptic vesicle membrane fusion complex in vitro. EMBO J 14:2317-2325.

Hayashi Y, Shi SH, Esteban JA, Piccini A, Poncer JC, Malinow R. 2000. Driving AMPA receptors into synapses by LTP and CaMKII: requirement for GluR1 and PDZ domain interaction. Science 287:2262-2267.

Henley J. 2001. Proteins involved in the synaptic organization of AMPA (alpha-amino-3-hydroxy-5-methylisoxazolepropionate) receptors. Biochem Soc Trans 29:485-488.

Hirbec H, Perestenko O, Nishimune A, Meyer G, Nakanishi S, Henley JM, Dev KK. 2002. The PDZ proteins PICK1, GRIP, and syntenin bind multiple glutamate receptor subtypes. Analysis of PDZ binding motifs. J Biol Chem 277:15221-15224.

Hirbec H, Francis JC, Lauri SE, Braithwaite SP, Coussen F, Mulle C, Dev KK, Couthino V, Meyer G, Isaac JT, Collingridge GL, Henley JM. 2003. Rapid and differential regulation of AMPA and kainate receptors at hippocampal mossy fibre synapses by PICK1 and GRIP. Neuron 37: $625-638$.

Hollmann M, Heinemann S. 1994. Cloned glutamate receptors. Annu Rev Neurosci 17:31-108.

Huntley GW, Vickers JC, Morrison JH. 1994. Cellular and synaptic localization of NMDA and non-NMDA receptor subunits in neocortex: organizational features related to cortical circuitry, function and disease. Trends Neurosci 17:536-543.

Ibrahim HM, Healy DJ, Hogg AJ Jr, Meador-Woodruff JH. 2000a. Nucleusspecific expression of ionotropic glutamate receptor subunit mRNAs and binding sites in primate thalamus. Brain Res Mol Brain Res 79:1-17.

Ibrahim HM, Hogg AJ Jr, Healy DJ, Haroutunian V, Davis KL, MeadorWoodruff JH. 2000b. Ionotropic glutamate receptor binding and subunit mRNA expression in thalamic nuclei in schizophrenia. Am J Psychiatry 157:1811-1823.

Imai C, Sugai T, Iritani S, Niizato K, Nakamura R, Makifuchi T, Kakita A Takahashi H, Nawa H. 2001. A quantitative study on the expression of synapsin II and N-ethylmaleimide-sensitive fusion protein in schizophrenic patients. Neurosci Lett 305:185-188.

Isaac JT, Nicoll RA, Malenka RC. 1995. Evidence for silent synapses: implications for the expression of LTP. Neuron 15:427-434

Itoh M, Nagafuchi A, Yonemura S, Kitani-Yasuda T, Tsukita S. 1993. The $220-\mathrm{kD}$ protein colocalizing with cadherins in non-epithelial cells is identical to ZO-1, a tight junction-associated protein in epithelial cells: cDNA cloning and immunoelectron microscopy. J Cell Biol 121:491-502.

Jones EG, Tighilet B, Tran BV, Huntsman MM. 1998. Nucleus- and cellspecific expression of NMDA and non-NMDA receptor subunits in monkey thalamus. J Comp Neurol 397:371-393.

Kharazia VN, Phend KD, Rustioni A, Weinberg RJ. 1996. EM colocalization of AMPA and NMDA receptor subunits at synapses in rat cerebral cortex. Neurosci Lett 210:37-40.

Kim $\mathrm{CH}$, Chung HJ, Lee HK, Huganir RL, 2001. Interaction of the AMPA receptor subunit GluR2/3 with PDZ domains regulates hippocampal long-term depression. Proc Natl Acad Sci USA 98:11725-11730.

Kohama SG, Urbanski HF. 1997. Distribution of glutamate receptor subunits in the primate temporal cortex and hippocampus. Brain Res 769:44-56

Kohler M, Kornau H, Seeburg P. 1994. The organization of the gene for the functionally dominant alpha-amino-3-hydroxy-5-methylisoxazole-4 propionic acid receptor subunit GluR-B. J Biol Chem 269:17367-17370.

Letts VA, Felix R, Biddlecome GH, Arikkath J, Mahaffey CL, Valenzuela A, Bartlett FS 2nd, Mori Y, Campbell KP, Frankel WN. 1998. The mouse stargazer gene encodes a neuronal $\mathrm{Ca} 2+$-channel gamma subunit. Nat Genet 19:340-347.

Liao D, Scannevin RH, Huganir R. 2001. Activation of silent synapses by rapid activity-dependent synaptic recruitment of AMPA receptors. J Neurosci 21:6008-6017.

Lin RC, Scheller RH. 2000. Mechanisms of synaptic vesicle exocytosis. Annu Rev Cell Dev Biol 16:19-49.

Lin WJ, Chang YF, Wang WL, Huang CY. 2001. Mitogen-stimulated TIS21 protein interacts with a protein-kinase-Calpha-binding protein rPICK1. Biochem J 354:635-643.

Linden DJ, Connor JA. 1995. Long-term synaptic depression. Annu Rev Neurosci 18:319-357.

Lothman EW, Rempe DA, Mangan PS. 1995. Changes in excitatory neurotransmission in the $\mathrm{CA} 1$ region and dentate gyrus in a chronic model of temporal lobe epilepsy. J Neurophysiol 74:841-848. 
Lue RA, Marfatia SM, Branton D, Chishti AH. 1994. Cloning and characterization of hdlg: the human homologue of the Drosophila discs large tumor suppressor binds to protein 4.1. Proc Natl Acad Sci USA 91: 9818-9822.

Luscher C, Xia H, Beattie EC, Carroll RC, von Zastrow M, Malenka RC, Nicoll RA. 1999. Role of AMPA receptor cycling in synaptic transmission and plasticity. Neuron 24:649-658.

Luthi A, Chittajallu R, Duprat F, Palmer MJ, Benke TA, Kidd FL, Henley JM, Isaac JT, Collingridge GL. 1999. Hippocampal LTD expression involves a pool of AMPARs regulated by the NSF-GluR2 interaction. Neuron 24:389-399.

Mangan PS, Rempe DA, Lothman EW. 1995. Changes in inhibitory neurotransmission in the CA1 region and dentate gyrus in a chronic model of temporal lobe epilepsy. J Neurophysiol 74:829-840.

Martin RF, Bowden DM. 1996. A stereotaxic template atlas of the macaque brain for digital imaging and quantitative neuroanatomy. Neuroimage 4:119-150.

McGlade-McCulloh E, Yamamoto H, Tan SE, Brickey DA, Soderling TR. 1993. Phosphorylation and regulation of glutamate receptors by calcium/calmodulin-dependent protein kinase II. Nature 362:640-642.

McInvale AC, Staudinger J, Harlan RE, Garcia MM. 2002. Immunolocalization of PICK1 in the ascending auditory pathways of the adult rat. J Comp Neurol 450:382-394.

Meador-Woodruff JH, Hogg AJ Jr, Smith RE. 2001. Striatal ionotropic glutamate receptor expression in schizophrenia, bipolar disorder, and major depressive disorder. Brain Res Bull 55:631-640.

Mirnics K, Lewis DA. 2001. Genes and subtypes of schizophrenia. Trends Mol Med 7:281-283.

Mirnics K, Middleton FA, Marquez A, Lewis DA, Levitt P. 2000. Molecular characterization of schizophrenia viewed by microarray analysis of gene expression in prefrontal cortex. Neuron 28:53-67.

Mirnics K, Middleton FA, Lewis DA, Levitt P. 2001. The human genome: gene expression profiling and schizophrenia. Am J Psychiatry 158:1384.

Munoz A, Woods TM, Jones EG. 1999. Laminar and cellular distribution of AMPA, kainate, and NMDA receptor subunits in monkey sensorymotor cortex. J Comp Neurol 407:472-490.

Nagase T, Ishikawa K, Nakajima D, Ohira M, Seki N, Miyajima N, Tanaka A, Kotani H, Nomura N, Ohara O. 1997. Prediction of the coding sequences of unidentified human genes. VII. The complete sequences of 100 new cDNA clones from brain which can code for large proteins in vitro. DNA Res 4:141-150.

Nagerl UV, Mody I, Jeub M, Lie AA, Elger CE, Beck H. 2000. Surviving granule cells of the sclerotic human hippocampus have reduced $\mathrm{Ca}(2+)$ influx because of a loss of calbindin- $\mathrm{D}(28 \mathrm{k})$ in temporal lobe epilepsy. J Neurosci 20:1831-1836.

Nishimune A, Isaac JT, Molnar E, Noel J, Nash SR, Tagaya M, Collingridge GL, Nakanishi S, Henley JM. 1998. NSF binding to GluR2 regulates synaptic transmission. Neuron 21:87-97.

Noel J, Ralph GS, Pickard L, Williams J, Molnar E, Uney JB, Collingridge GL, Henley JM. 1999. Surface expression of AMPA receptors in hippocampal neurons is regulated by an NSF-dependent mechanism. Neuron 23:365-376.

Ohara O, Nagase T, Ishikawa K, Nakajima D, Ohira M, Seki N, Nomura N. 1997. Construction and characterization of human brain cDNA libraries suitable for analysis of cDNA clones encoding relatively large proteins. DNA Res 4:53-59.

Ohnuma T, Kato H, Arai H, Faull RL, McKenna PJ, Emson PC. 2000. Gene expression of PSD95 in prefrontal cortex and hippocampus in schizophrenia. Neuroreport 11:3133-3137.

Osten P, Srivastava S, Inman GJ, Vilim FS, Khatri L, Lee LM, States BA, Einheber S, Milner TA, Hanson PI, Ziff EB. 1998. The AMPA receptor GluR2 C terminus can mediate a reversible, ATP-dependent interaction with NSF and alpha- and beta-SNAPs. Neuron 21:99-110.

Otmakhova NA, Otmakhov N, Lisman JE. 2002. Pathway-specific properties of AMPA and NMDA-mediated transmission in CA1 hippocampal pyramidal cells. J Neurosci 22:1199-1207.

Paxinos G, Huang X, Toga AW. 2000. The rhesus monkey brain in stereotaxic coordinates. London: Academic Press.

Perez JL, Khatri L, Chang C, Srivastava S, Osten P, Ziff EB. 2001. PICK1 targets activated protein kinase Calpha to AMPA receptor clusters in spines of hippocampal neurons and reduces surface levels of the AMPA-type glutamate receptor subunit 2. J Neurosci 21:5417-5428.

Petralia RS, Wenthold RJ. 1992. Light and electron immunocytochemical localization of AMPA-selective glutamate receptors in the rat brain. J Comp Neurol 318:329-354.

Puchalski RB, Louis JC, Brose N, Traynelis SF, Egebjerg J, Kukekov V,
Wenthold RJ, Rogers SW, Lin F, Moran T, Morrison J, Heinemann S. 1994. Selective RNA editing and subunit assembly of native glutamate receptors. Neuron 13:131-147.

Puschel AW, O'Connor V, Betz H. 1994. The N-ethylmaleimide-sensitive fusion protein (NSF) is preferentially expressed in the nervous system. FEBS Lett 347:55-58.

Rempe DA, Mangan PS, Lothman EW. 1995. Regional heterogeneity of pathophysiological alterations in CA1 and dentate gyrus in a chronic model of temporal lobe epilepsy. J Neurophysiol 74:816-828.

Rothman JE. 1994. Intracellular membrane fusion. Adv Second Messenger Phosphoprotein Res 29:81-96.

Selig DK, Hjelmstad GO, Herron C, Nicoll RA, Malenka RC. 1995. Independent mechanisms for long-term depression of AMPA and NMDA responses. Neuron 15:417-426.

Sheng M, Kim E. 1996. Ion channel associated proteins. Curr Opin Neurobiol 6:602-608.

Sheng M, Lee SH. 2001. AMPA receptor trafficking and the control of synaptic transmission. Cell 105:825-828.

Sheng M, Pak D. 2000. Ligand-gated ion channel interactions with cytoskeletal and signaling proteins. Annu Rev Physiol 62:755-778.

Shi SH. 2001. Amersham Biosciences \& Science Prize. AMPA receptor dynamics and synaptic plasticity. Science 294:1851-1852.

Shi SH, Hayashi Y, Petralia RS, Zaman SH, Wenthold RJ, Svoboda K, Malinow R. 1999. Rapid spine delivery and redistribution of AMPA receptors after synaptic NMDA receptor activation. Science 284:18111816.

Shi S, Hayashi Y, Esteban JA, Malinow R. 2001. Subunit-specific rules governing AMPA receptor trafficking to synapses in hippocampal pyramidal neurons. Cell 105:331-343.

Singer D, Biel M, Lotan I, Flockerzi V, Hofmann F, Dascal N. 1991. The roles of the subunits in the function of the calcium channel. Science 253:1553-1557.

Song I, Kamboj S, Xia J, Dong H, Liao D, Huganir RL. 1998. Interaction of the N-ethylmaleimide-sensitive factor with AMPA receptors. Neuron 21:393-400.

Srivastava S, Osten P, Vilim FS, Khatri L, Inman G, States B, Daly C, DeSouza S, Abagyan R, Valtschanoff JG, Weinberg RJ, Ziff EB. 1998. Novel anchorage of GluR2/3 to the postsynaptic density by the AMPA receptor-binding protein ABP. Neuron 21:581-591.

Staudinger J, Lu J, Olson EN. 1997. Specific interaction of the PDZ domain protein PICK1 with the $\mathrm{COOH}$ terminus of protein kinase C-alpha. J Biol Chem 272:32019-32024.

Takumi Y, Ramirez-Leon V, Laake P, Rinvik E, Ottersen OP. 1999. Different modes of expression of AMPA and NMDA receptors in hippocampal synapses. Nat Neurosci 2:618-624.

Torres GE, Yao WD, Mohn AR, Quan H, Kim KM, Levey AI, Staudinger J, Caron MG. 2001. Functional interaction between monoamine plasma membrane transporters and the synaptic PDZ domain-containing protein PICK1. Neuron 30:121-134.

Wei XY, Perez-Reyes E, Lacerda AE, Schuster G, Brown AM, Birnbaumer L. 1991. Heterologous regulation of the cardiac $\mathrm{Ca} 2+$ channel alpha 1 subunit by skeletal muscle beta and gamma subunits. Implications for the structure of cardiac L-type $\mathrm{Ca} 2+$ channels. J Biol Chem 266: 21943-21947.

Wenthold RJ, Yokotani N, Doi K, Wada K. 1992. Immunochemical characterization of the non-NMDA glutamate receptor using subunitspecific antibodies. Evidence for a hetero-oligomeric structure in rat brain. J Biol Chem 267:501-507.

Whiteheart SW, Rossnagel K, Buhrow SA, Brunner M, Jaenicke R, Rothman JE. 1994. N-ethylmaleimide-sensitive fusion protein: a trimeric ATPase whose hydrolysis of ATP is required for membrane fusion. J Cell Biol 126:945-954.

Xia J, Zhang X, Staudinger J, Huganir RL. 1999. Clustering of AMPA receptors by the synaptic PDZ domain-containing protein PICK1. Neuron 22:179-187.

Xia J, Chung HJ, Wihler C, Huganir RL, Linden DJ. 2000. Cerebellar long-term depression requires PKC-regulated interactions between GluR2/3 and PDZ domain-containing proteins. Neuron 28:499-510.

Xu L, Tanigawa H, Fujita I. 2003. Distribution of alpha-amino-3-hydroxy5-methyl-4-isoxazolepropionate-type glutamate receptor subunits (GluR2/3) along the ventral visual pathway in the monkey. J Comp Neurol 456:396-407.

Zhu JJ, Esteban JA, Hayashi Y, Malinow R. 2000. Postnatal synaptic potentiation: delivery of GluR4-containing AMPA receptors by spontaneous activity. Nat Neurosci 3:1098-1106. 